\title{
Using Artificial Neural Networks to Support the Decision-Making Process of Buying Call Options Considering Risk Appetite
}

\author{
Radosław Puka (D), Bartosz Lamasz (D) and Marek Michalski *(D) \\ Faculty of Management, AGH University of Science and Technology, 30-059 Cracow, Poland; \\ rpuka@zarz.agh.edu.pl (R.P.); blamasz@zarz.agh.edu.pl (B.Ł.) \\ * Correspondence: Marek.Michalski@zarz.agh.edu.pl; Tel.: +48-600-266-227
}

Citation: Puka, R.; Łamasz, B.;

Michalski, M. Using Artificial Neural Networks to Support the Decision-Making Process of Buying Call Options Considering Risk Appetite. Energies 2021, 14, 8494. https://doi.org/10.3390/en14248494

Academic Editor: Konrad Zajkowski

Received: 18 November 2021

Accepted: 11 December 2021

Published: 16 December 2021

Publisher's Note: MDPI stays neutral with regard to jurisdictional claims in published maps and institutional affiliations.

Copyright: (c) 2021 by the authors. Licensee MDPI, Basel, Switzerland. This article is an open access article distributed under the terms and conditions of the Creative Commons Attribution (CC BY) license (https:// creativecommons.org/licenses/by/ $4.0 /)$.

\begin{abstract}
During the COVID-19 pandemic, uncertainty has increased in many areas of both business supply and demand, notably oil demand and pricing have become even more unpredictable than before. Thus, for companies that buy large quantities of oil, effective oil price risk management is crucial for business success. Nevertheless, businesses' risk appetite, specifically willingness to accept more risk to achieve desired business benefits, varies significantly. The aim of this paper is to deepen the analysis of the effectiveness of employing artificial neural networks (ANNs) in hedging against oil price changes by searching for buy signals for European WTI (West Texas Intermediate) crude oil call options, while taking into account the level of risk appetite. The number of generated buy signals decreases with increasing risk appetite, and thus the amount of capital necessary to buy options decreases. However, the results show that fewer buy signals do not necessarily translate into lower returns generated by networks in a given class. Thus, higher levels of return on the purchase of call options may be obtained. The conducted analyses clearly proved that ANNs can be a useful tool in the process of managing WTI crude oil price change risk. Using the analyzed network parameters, up to $29.9 \%$ of the theoretical maximum possible profit from buying options every day was obtained in the test set. Furthermore, all proposed networks generated some profit for the test set. The values of all indicators used in the analyses confirm that the ANNs can be effective regardless of the level of risk appetite, so in this respect they may be described as a universal decision support tool.
\end{abstract}

Keywords: crude oil price risk; commodity options; artificial neural networks (ANNs); support decision-making; COVID-19

\section{Introduction}

In 2020, the COVID-19 pandemic caused an extraordinary drop in oil demand. It has rebounded since then and prices have reached multi-year highs. Strong demand for oil is expected to continue, barring unforeseen surges in the number of sick or the severity of symptoms and more lockdowns. Under these conditions, forecasting oil prices is even more difficult than usual, when uncertainty is caused mainly by the number of worldwide market players and a largely unpredictable, often opaque and political decision process on the supply side. This will likely increase large customers' interest in shielding themselves from price risk by turning to long-term contracts and options.

There are many studies on the effects of COVID-19 on price risk in financial and commodity markets [1-3]. Increasingly, attention has been drawn to the fact that the energy sector is one of those most noticeably affected by the effects of the pandemic [4]. Some of research also focuses on the rising price risk in relation to the crude oil market. Akhtaruzzaman et al. [5] showed that in general, oil supply industries benefit from increases in oil price risk, whereas customers and financial industries react negatively to positive oil price shocks. Sharif et al. [6] used data from 21st January 2020 to 30 March 2020 to show sensitivity of the US stock market, the US economic policy and the US geopolitical risk to 
the combined shocks of the COVID-19 and oil volatility shocks. In turn, Abuzayed and Al-Fayoumi [7], using daily data from January 2017 until May 2020, examined oil price extreme tail risk spillover to individual Gulf Cooperation Council (GCC) stock markets and quantified this spillover's shift before and during the COVID-19 pandemic. Among other things, they showed that the effect of oil price systemic risk on GCC stock market returns was significantly larger during COVID-19 than before the pandemic.

Issues related to the consequences of the risk of changes in oil prices were a popular topic of scientific research even before the coronavirus pandemic. Researchers analyzed the impact of oil price fluctuations on macroeconomic aggregates such as the level of investment, stock prices and returns [8-13], inflation rate [14], industrial production and exchange rates [15-19], as well as financial and monetary policy [20]. There has also been a large number of studies concerning the impact of crude oil prices on commodities such as: energy [21-25] and agricultural commodities [26-29], copper, gold [30,31], silver, zinc, platinum and palladium [32] and molybdenum [33].

Various methods may be employed for price risk mitigation, notably diversification, stockpiling, forward and futures contracts as well as options. In the oil market there are limited opportunities for diversification, since in most applications of oil has few substitutes, especially in the short term. Stockpiling is limited by storage capacity and may be impractical, whereas forward and futures contracts have the disadvantage of requiring exercising the contract, even if results in a loss. Options have the advantage of giving - as the name implies - an option to buy or sell a set quantity at a given price, without the obligation. This is especially true for the world energy commodities market, where price fluctuations pose a great liquidity risk for production companies.

However, the effective use of options in price risk management is nontrivial. Their effectiveness depends on numerous parameters such as strike price, option opening and expiry date. That is why it is important to select tools and techniques that increase the probability of choosing options that protect against unfavorable price fluctuations. Therefore, the aim of this paper is to deepen the analysis of the effectiveness of employing artificial neural networks in the search for buy signals for European WTI (West Texas Intermediate) crude oil call options by changing ANN parameters related to risk appetite.

Artificial neural networks are we well suited for this type of problems due to their inherent ability to model complex non-linear relationships. Importantly, these relationships do not need to be explicitly identified. ANNs' effectiveness hinges on the availability of large amounts of data to train the networks. In this case, these data are provided by the liquid WTI crude oil options market.

There have been many attempts to use ANNs for price risk mitigation on the oil market. For example, Azadeh et al. [34] showed that in terms of mean absolute percentage error (MAPE), ANNs can substantially outperform fuzzy regression. For the prediction of WTI crude oil prices, Chiroma et al. [35] proposed an approach based on a genetic algorithm and neural network (GA-NN). Mann-Whitney test results indicated no significant difference between median WTI crude oil prices predicted by GA-NN and prices observed over a three-year period. Wang and Wang [36] attempted to forecast crude stock and oil prices using an amalgamation of Elman recurrent neural networks (ERNN) with stochastic time effective function (ST) and multilayer perceptron (MLP) to develop a forecasting model, called ST-ERNN. Forecasts based on this model were better than from ERNN and backpropagation neural network (BPNN) models. Liu and others [37] found that an enhanced Artificial Bee Colony with Back Propagation (BP) natural network model is better than Monte Carlo Simulation at predicting implied volatility.

Numerous studies [38-47] show that ANNs are an effective tool for forecasting crude oil prices. However, the aforementioned studies focused mostly on oil price predictions, which do not necessarily lead to successful investment strategies as shown by the authors in previous studies [48,49] (and others [50]). This paper builds on an approach proposed by the authors in these studies to analyze the effect of an ANN parameter expressing risk appetite. The actual concept of risk appetite is equated with the final result (payoff) 
obtained as a result of purchasing call options. A company determines its risk appetite by specifying the minimum expected payoff value that must be exceeded in order to consider a given position favorable from the perspective of its objectives. The higher this threshold (higher risk appetite), the lower the total number of options acquired under the implemented strategy. As a result, the probability of opening a position in an option that would protect the company from large losses due to significant fluctuations in commodity (oil) prices will decrease. Therefore, the main objective of the presented research was to try to increase the probability of making a correct decision in purchasing a call option by optimizing the value of the indicator equal to the ratio of the total sum of returns obtained from the purchased call options to the sum of returns on all positions in profitable call options during the analyzed period. The proposed indicator should be maximized so that the number of correctly made decisions results in the highest possible level of return on investment in options, while taking into account the company's preferred risk appetite. To the best of our knowledge, the proposed analysis has so far not been carried out in any previous studies.

The article is structured as follows: Section 2 contains the proposed method. The data and its properties are presented in Section 3. Empirical results are discussed in Section 4. Section 5 contains the summary, conclusions and future research directions.

\section{Proposed Method}

We propose changing an ANN parameter expressing risk appetite to improve the effectiveness of hedging against the risk of oil price increases by taking long positions in call options. Section 2.1 describes the characteristics of the chosen ANN models. In Section 2.2 we expound the concept of using options for price risk mitigation. Finally, in Section 2.3, we present the reasoning behind the chosen performance indicators and methods for calculating them.

\subsection{Artificial Neural Networks}

Artificial neural networks are modelled on neurons in the brain, represented by logistic units connected into a so-called neural network, where input and output nodes are separated by one or more hidden layers. In this case, inputs are market conditions and outputs are the decision whether to buy options. The network is trained on a subset of historic data and subsequently its performance is evaluated on the remaining data. Neural networks differ in architecture, i.e., the number of features and outputs, layers and activation functions that define the decision process-choosing these well is a non-trivial process that has a large impact on performance. The quantity and quality of historical data also plays a significant role-very large, representative, non-redundant data sets are best.

Given a training set $(x(i), y(i))$ for $i=1, \ldots, m$, where $\mathrm{m}$ is the number of variables, $x^{\prime}$ s are the "input" variables and y's the "output" variables, a hypothesis function $\mathrm{h}_{\theta}(x)$ is proposed and its parameters $\theta$ are calculated using various algorithms to minimize a cost function $J$. The cost function represents the difference between the predicted and actual output given by the equation (this and alternative methods are explained in [51]):

$$
J=\frac{1}{2 m} \sum_{i=1}^{m}\left(\mathrm{~h}_{\theta}\left(x^{(i)}\right)-y^{(i)}\right)^{2}
$$

The ANN learning process is relying on backpropagation, to find values of $\Theta$, which is a matrix of $\theta$ parameters that minimize the cost function by minimizing individual errors $\delta_{j}{ }^{(1)}$, where $j$ is the number of the node in layer $l$. The objective of minimizing the cost function $J$ by finding parameters $\Theta$ requires an approximation of partial derivatives of $J(\Theta)[52]:$

$$
\frac{\partial}{\partial \Theta_{i, j}^{(l)}} J(\Theta)
$$


where: $J$-cost function, $\Theta_{i, j}^{(l)}$-ANN parameters matrix, $i-$ ANN parameter index, $m$ - number of ANN parameters $i, j-A N N$ layer index.

Derivatives are computed using the backpropagation algorithm applied to the training set. For every feature " $i$ " in turn, the error in the approximation is computed as [53]:

$$
\Delta^{(l)}:=\Delta^{(l)}+\delta^{(l+1)}\left(a^{(l)}\right)^{T}
$$

where: $\Delta$ —error matrix, $\left(a^{(l)}\right)^{T}$ —transposed activation units vector of layer $l, \delta_{\mathrm{j}}^{(l+1)}$ —errors in the next layer.

In practice, regularization (parameter $\lambda$ ) must also be used to avoid overfitting the data and minimize errors. Otherwise, only accuracy on the training set is maximized, while fit to other data may be poor. The authors used Statistica software by TIBCO Software Inc. (Palo Alto, CA, USA) to build and train artificial neural networks using multilayer perceptron to model non-linear relationships between input and output variables. A three-layer network was chosen with one input, one output and one hidden layer.

The Broyden-Fletcher-Goldfarb-Shanno algorithm was used for training the ANN. It is an optimization algorithm that starts with an initial guess of parameters and iteratively improves upon it (using data from the training set) by searching for a better solution in direction $\mathrm{p}_{\mathrm{k}}$ as defined by [54]:

$$
\mathrm{B}_{\mathrm{k}} \mathrm{p}_{\mathrm{k}}=\nabla \mathrm{f}\left(\mathrm{x}_{\mathrm{k}}\right)
$$

where: $\mathrm{B}_{\mathrm{k}}$-approximation of the Hessian matrix, $\mathrm{p}_{\mathrm{k}}$ —search direction, $\nabla \mathrm{f}\left(\mathrm{x}_{\mathrm{k}}\right)$ - gradient of given function $\mathrm{f}$ at point $\mathrm{x}_{\mathrm{k}}$.

The ANN was employed in solving a classification problem of whether to buy call options. We experimented with different activation functions (in the hidden and output layer) and number of neurons (in the hidden layer) to find networks that resulted in the best predictions as determined by performance indicators defined in Section 2.3.

\subsection{Price Risk Mitigation Using Options}

Options are non-linear derivatives that offer great hedging possibilities against price risk. Opening a position on the option market and treating it as a form of hedging against price fluctuations is usually done in such a way that the position in the option covers any losses on the underlying asset market. For example, a company that is concerned about an increase in the price of crude oil with a future delivery date may open a long position with a call option on that commodity. In the event of an increase in the value of crude oil relative to the agreed strike price, it will receive a non-negative payment. In turn, an oil price lower than the strike price on the contract expiry date will mean that the right to exercise the option will not be exercised. The final result (payoff) for the buyer of the call option can therefore be calculated according to the following formula:

$$
v_{c}=\max \{F-K ; 0\}-o p_{c},
$$

where: $v_{c}$-the final results (payoff); $F$-the future price of crude oil on the day of the option's expiration; $K$-strike price of the option; $o p_{c}$-option premium (for the strike price $K)$ for observation $c$.

Equation (5) shows that by taking long positions in call options, the maximum loss in the options market is known. For a call option's buyer, the maximum loss is equal to the unit option premium multiplied by the number of options that were bought. This allows option buyers to plan their future budget without exposing themselves to unforeseen price movements, such as those that the buyers of futures must accommodate, since margin account requirements change with the price of oil, which can affect total cost. It is also worth noting that for options, this amount is known, and it is up to the buyer to decide whether or not to accept this upfront cost [49].

In our study, we focus on WTI crude oil call options available on the New York Mercantile Exchange (NYMEX). The analyses were carried out on the same data as the 
authors' previous studies [48,49], from 16 June 2009 to 14 February 2020, so that the results of various approaches could be compared. We include only ATM (at-the-money) options, i.e., those with a strike price identical (or very close) to the WTI future price on a given day. ATM options data were sourced from the QuikStrike platform by the CME Group [55]. The WTI Light Sweet Crude Oil future contract (symbol: CL) in crude oil options on NYMEX is the underlying asset. Each contract corresponds to 1000 barrels. The contracts trade in steps of one cent per barrel [56].

These options expire 3 business days before the underlying futures contract (CL). The analyzed European Style option contracts are settled in cash on the expiration day $[49,57]$. The payout from this transaction is the settlement price of the CL contract minus the strike price, multiplied by a thousand barrels, or zero, whichever is greater [57]. We analyzed options based on the price of the nearest futures contract in crude oil with days to expiry ranging from 34 to 1 . We used Black's model for option pricing [58-61]. Alternative approaches were explored by Yousaf, R. et al. and Khan, R. et al. in $[62,63]$.

\subsection{Perfomance Indicators}

We kept the assumption from our previous studies $[48,49]$ that only one option contract may be bought per day-this was done to be able to compare results. However, the performance indicators were modified to take into account different levels of risk appetite. Indicators were divided and described according to two categories. The first category was used for initial data analysis (these data were split into two sets: training and testing). Next, indicators from the second category helped assess the quality of the proposed method in terms of its suitability for supporting the decision-making process of buying call options.

Let $C$ be a set, whose elements are observations and $C^{\prime}$ is a subset of the set $C\left(C^{\prime} \subset C\right)$.

1. Indicators referring to the maximum profit and total results that can be achieved in a given period by taking long positions in call options:

(a) $\quad \operatorname{MPR}_{(\mathbf{x})}$ (Maximum profit for a range)—-the sum of profits from the long call options for all days for which the final result was greater than $\mathrm{x}$; the value of $\mathrm{MPR}_{(x)}$ index is calculated as follows:

$$
\operatorname{MPR}_{(\mathrm{x})}=\sum_{c \in C^{\prime}} z r_{c} \cdot v_{c}
$$

where $c$ is an element of the set $C^{\prime}, v_{c}$ denotes the value of the final results from the purchase of a call option for observation c. It is described by Equation (5) and $z r_{c}$ denotes a binary variable:

$$
z r_{c}=\left\{\begin{array}{l}
1, \text { if } v_{c}>x \\
0, \text { if } v_{c} \leq 0
\end{array}\right.
$$

The value of the indicator described by Equation (6), for which $x=0$ is the maximum profit that can be achieved in the analyzed period. This value is an important point of reference for us, so we decided to call it MP without " $R$ " and subscript $\left(\mathrm{MPR}_{(0)}=\mathrm{MP}\right)$

(b) $\operatorname{pMPR}_{(\mathrm{x})}$ (percent of maximum profit in range) - ratio of $\mathrm{MPR}_{(\mathrm{x})}$ to total profit, which is equal to the sum of all long call option positions that were greater than $0(\mathrm{MP})$ :

$$
\operatorname{pMPR}_{(\mathrm{x})}=\frac{\operatorname{MPR}_{(\mathrm{x})}}{\mathrm{MP}} \cdot 100 \%
$$

When $x=0, \mathrm{pMPR}_{(0)}$ is equal to $100 \%$, as expected. 
(c) $\operatorname{pNMPR}_{(x)}$-indicator showing the ratio of the number of days on which the options made profit in a range $(x, \infty)$ to the number of options that made profit in the entire $(0, \infty)$ range:

$$
\operatorname{pNMPR}_{(\mathrm{x})}=\frac{\sum_{c \in C^{\prime}} z r_{c}}{\sum_{c \in C^{\prime}} z_{c}} \cdot 100 \%
$$

When $x=0$, we obtain $\operatorname{pNMPR}_{(0)}=100 \%$ as expected.

(d) AR (Average return) - the total value of the final result from the long call options on each successive day of quotation in a given period; the $A R$ indicator is described by the following equation:

$$
\mathrm{AR}=\sum_{c \in C^{\prime}} v_{c}
$$

2. Indicators presenting the results obtained with the use of a given neural network.

(a) $\quad \operatorname{EPR}_{(\mathbf{x})}($ Expected profit for a range) - the result of the neural network operation on a subset $C^{\prime}$ :

$$
\operatorname{EPR}_{(\mathrm{x})}=\sum_{c \in C^{\prime}} o_{c} \cdot v_{c}
$$

where $o_{\mathcal{c}}$ is described by the equation:

$$
o_{c}=\left\{\begin{array}{l}
1, \text { if for observation } c, \text { a call option was bought } \\
0, \text { if for observation } c, \text { a call option was not bought }
\end{array}\right.
$$

When determining the value of $\mathrm{EPR}_{(\mathrm{x})}$, we reject all observations $\mathrm{v}_{\mathrm{c}}$ that were in the range $(0 ; x]$ and for which the network generated a buy signal $\left(o_{c}=1\right)$. This is done because taking these observations into account would cause the value of $\operatorname{EPR}_{(\mathrm{x})}$ to be overestimated by values that were misclassified. The purpose of the network is to find signals to buy call options above a predetermined level $x$. Thus, all signals in the range $(0 ; x]$ should be considered unattractive from the perspective of the company's risk appetite.

(b) $\% \operatorname{MPR}_{(\mathrm{x})}$ (percent of maximum profit for a range)-the percentage of the best possible result $\left(M P R_{(x)}\right)$ achieved by this method $\left(E P R_{(x)}\right)$ :

$$
\% \operatorname{MPR}_{(\mathrm{x})}=\frac{\operatorname{EPR}_{(\mathrm{x})}}{\operatorname{MPR}_{(\mathrm{x})}} \cdot 100 \%
$$

(c) $\mathrm{pNEP}$ - the indicator that shows the percentage of all available call options that were purchased on the basis of the used networks; pNEP was defined with the following equation:

$$
\mathrm{pNEP}=\frac{1}{\left|C^{\prime}\right|} \sum_{c \in C^{\prime}} o_{c}
$$

The values of all the above indicators were established for networks with different activation functions and various numbers of neurons in the hidden layer. The data were divided into a training set and a test set for both performing the initial data evaluation (based on the first category of indicators) and assessing the networks' effectiveness in hedging against oil price fluctuations (based on the second category of indicators).

\section{Data and Preliminary Analysis}

In the empirical part of the study, we analyze the final results in European style long call options over 10 years (from 16 June 2009 to 14 February 2020) based on ATM options and settlement prices for the nearest crude oil futures contract. We focused on prices 
of the first available futures contracts, thus for every month, we obtained 28-32 results2630 results in total. The parameters of options (options premium, option exercise prices and option expiry dates) were from the NYMEX (New York Mercantile Exchange) and QuikStrike software. The values of option premiums and option exercise prices allowed us to calculate the final result for the buyer of European call options. The difference between the option premium and the payout function was calculated using Equation (5)).

Observations were divided into a training set and a test set using a ratio of 3 to 1 , respectively. The training set consisted of continuous observations from 17 September 2009 to 14 July 2017. The test set covered data from 17 July 2017 to 14 February 2020. Descriptive statistics of WTI futures prices, long call final results (in USD per barrel) and option premiums were included in [49]. Long call final results were also subjected to a more detailed analysis, and its results are shown in Tables 1 and 2.

Table 1. Numbers of observations, total returns and AR values for long call options.

\begin{tabular}{|c|c|c|c|c|c|}
\hline \multirow[b]{2}{*}{$\begin{array}{l}\text { Net Result Range } \\
\text { (USD per Barrel } \\
\text { per Option) }\end{array}$} & \multicolumn{2}{|c|}{ Training Set } & \multicolumn{2}{|c|}{ Test Set } & \\
\hline & $\begin{array}{l}\text { Numbers of } \\
\text { Observations }\end{array}$ & $\begin{array}{c}\text { Total } \\
\text { Returns } \\
\left(10^{3} \text { USD) }\right.\end{array}$ & $\begin{array}{l}\text { Numbers of } \\
\text { Observations }\end{array}$ & $\begin{array}{c}\text { Total } \\
\text { Returns } \\
\left(10^{3} \text { USD) }\right.\end{array}$ & \\
\hline$(-\infty ;-2.5]$ & 144 & -443.68 & 13 & -45.26 & \\
\hline$(-2.5 ;-2]$ & 156 & -346.87 & 38 & -83.50 & \\
\hline$(-2 ;-1.5]$ & 297 & -513.53 & 68 & -115.68 & \\
\hline$(-1.5 ;-1]$ & 313 & -391.37 & 114 & -143.90 & Loss \\
\hline$(-1 ;-0.5]$ & 251 & -189.24 & 102 & -79.33 & \\
\hline$(-0.5 ; 0]$ & 133 & -39.36 & 73 & -19.03 & \\
\hline Sum & 1294 & -1924.05 & 408 & -486.69 & \\
\hline$(0 ; 0.5]$ & 109 & 25.33 & 64 & 15.11 & \\
\hline$(0.5 ; 1]$ & 102 & 76.68 & 46 & 33.27 & \\
\hline$(1 ; 1.5]$ & 71 & 86.82 & 35 & 43.40 & \\
\hline$(1.5 ; 2]$ & 71 & 123.60 & 30 & 50.58 & Profit \\
\hline$(2 ; 2.5]$ & 59 & 133.47 & 28 & 62.34 & \\
\hline$(2.5 ;+\infty)$ & 260 & 1200.97 & 53 & 190.79 & \\
\hline Sum & 672 & 1646.86 & 256 & 395.49 & \\
\hline AR & & -277.19 & & -91.2 & \\
\hline
\end{tabular}

Notes: the training set data are from 17 September 2009 to 14 July 2017; the test set from 17 July 2017 to 14 February 2020.

Table 1 presents data broken down into ranges based on the level of returns from entering into long call option contracts. These were broken down into 12 ranges- 6 each for losses and gains. For each one of them, the number of observations and total returns were determined for both the training and test set. The values of the AR indicator, which show that the total sum of returns was negative for both the training set and the test set, were placed at the end of Table 1.

In terms of net losses, the largest number of observations were recorded in the range of $(-1.5 ;-1]$ USD per barrel per option for both the training and test sets. For the test set, this interval also had the largest total losses. In the case of the training set, the greatest total losses were generated in the range of $(-2 ;-1.5$ ] USD loss per barrel per option.

In turn, the highest total profits were generated by options, which generated a profit of at least 2.5 USD per batter per option. The largest number of observations were in the range of $(2.5 ; \infty)$ for the training set and $(0 ; 0.5]$ for the test set.

The number of observations generating profits and losses is also worth noting-the buying of a call option resulted in a loss almost twice as often than in a profit. Thus, the approach of indiscriminately buying call options would result in a net loss.

The data from Table 1 were converted into percentages, with profits and losses for both the training and the test set calculated separately. In this approach, 100\% was taken to be the number of all observations resulting in a profit (or loss) as well as the sum of all long call final results giving profit (or loss). Table 2 shows these percentages. 
Table 2. Percentage of all observations and total returns for long call options.

\begin{tabular}{ccccc}
\hline & \multicolumn{2}{c}{ Training Set } & \multicolumn{2}{c}{ Test Set } \\
\cline { 2 - 5 } Range & $\begin{array}{c}\text { Percentage of All } \\
\text { Observations } \\
\text { (Loss or Profit) }\end{array}$ & $\begin{array}{c}\text { Percentage of } \\
\text { Total Returns } \\
\text { (Loss or Profit) }\end{array}$ & $\begin{array}{c}\text { Percentage of All } \\
\text { Observations } \\
\text { (Loss or Profit) }\end{array}$ & $\begin{array}{c}\text { Percentage of } \\
\text { Total Returns } \\
\text { (Loss or Profit) }\end{array}$ \\
\hline$(-\infty ;-2.5]$ & $11 \%$ & $23 \%$ & $3 \%$ & $9 \%$ \\
$(-2.5 ;-2]$ & $12 \%$ & $18 \%$ & $9 \%$ & $17 \%$ \\
$(-2 ;-1.5]$ & $23 \%$ & $27 \%$ & $17 \%$ & $24 \%$ \\
$(-1.5 ;-1]$ & $24 \%$ & $20 \%$ & $28 \%$ & $30 \%$ \\
$(-1 ;-0.5]$ & $19 \%$ & $10 \%$ & $25 \%$ & $16 \%$ \\
$(-0.5 ; 0]$ & $10 \%$ & $2 \%$ & $18 \%$ & $4 \%$ \\
$(0 ; 0.5]$ & $16 \%$ & $2 \%$ & $25 \%$ & $8 \%$ \\
$(0.5 ; 1]$ & $15 \%$ & $5 \%$ & $18 \%$ & $11 \%$ \\
$(1 ; 1.5]$ & $11 \%$ & $5 \%$ & $14 \%$ & $13 \%$ \\
$(1.5 ; 2]$ & $11 \%$ & $8 \%$ & $12 \%$ & $16 \%$ \\
$(2 ; 2.5]$ & $9 \%$ & $8 \%$ & $11 \%$ & $48 \%$ \\
\hline
\end{tabular}

The summary presented in Table 2 confirms that in the case of the training set, a large number of final results in call options fell into extreme ranges ( $11 \%$ and $39 \%)$. This distribution looks completely different for the test set. This was especially evident in the range with losses over USD 2.50 on a single position, which accounted for only $3 \%$ of all positions for the buyer of the call option. This is undoubtedly a consequence of much lower option costs in the period covering the test set, as in over $75 \%$ of cases they did not exceed the level of USD 2 per barrel [49]. In addition, the percentage share of long call final results in total profits or losses is much higher for the extreme ranges from the training set than for the test set. In particular, this is the case for the final results exceeding USD 2.5, which accounted for nearly $75 \%$ of the total return generated by all profit-making options in the training set. In the case of the test set, the share of the total profit from this highest range accounted for less than half of the total return, which was in turn a consequence of much lower fluctuations in WTI oil prices during the test set period.

These relationships are also illustrated in Figure 1, which clearly shows the scale of differences in the number of positions and levels of returns for extreme ranges in the training and test set. It is also worth noting that during the entire analyzed period, the positions for which the final result was in the range $(2.5 ; \infty)$ largely accounted for the total level of profits. This is due to the unlimited profits that the buyer of a call option may realize on an increase in the value of the underlying asset relative to the agreed strike price. On the other hand, items accompanied by a very large drop in asset prices did not cause very large losses. Their level was limited to the value of the option premium, for which the average oscillated between USD 1.5-1.7 per barrel [49].

In our considerations, we assumed that increasing the risk appetite will result in a reduction in the number of call options that were purchased, and thus increase the probability of situations arising, in which hedging against significant price fluctuations will not be achieved. In order to analyze the impact of risk appetite on the final result of the hedging entity (the number of purchased call options and the level of return on investment relative to the maximum return value), the following three boundaries were adopted:

- $\quad$ - -with this value, each option for which payoff was non-negative was assigned to the set for which a buy signal should be generated; this value reflects a low-risk appetite: class I.

- $\quad$ 0.5 - buy signals should be generated only for options with payoff exceeding 0.5 USD; this option reflects an average risk appetite: class II.

- 1-buy signals should be generated only options with payoff above $\$ 1$; this option represents a high-risk appetite: class III. 


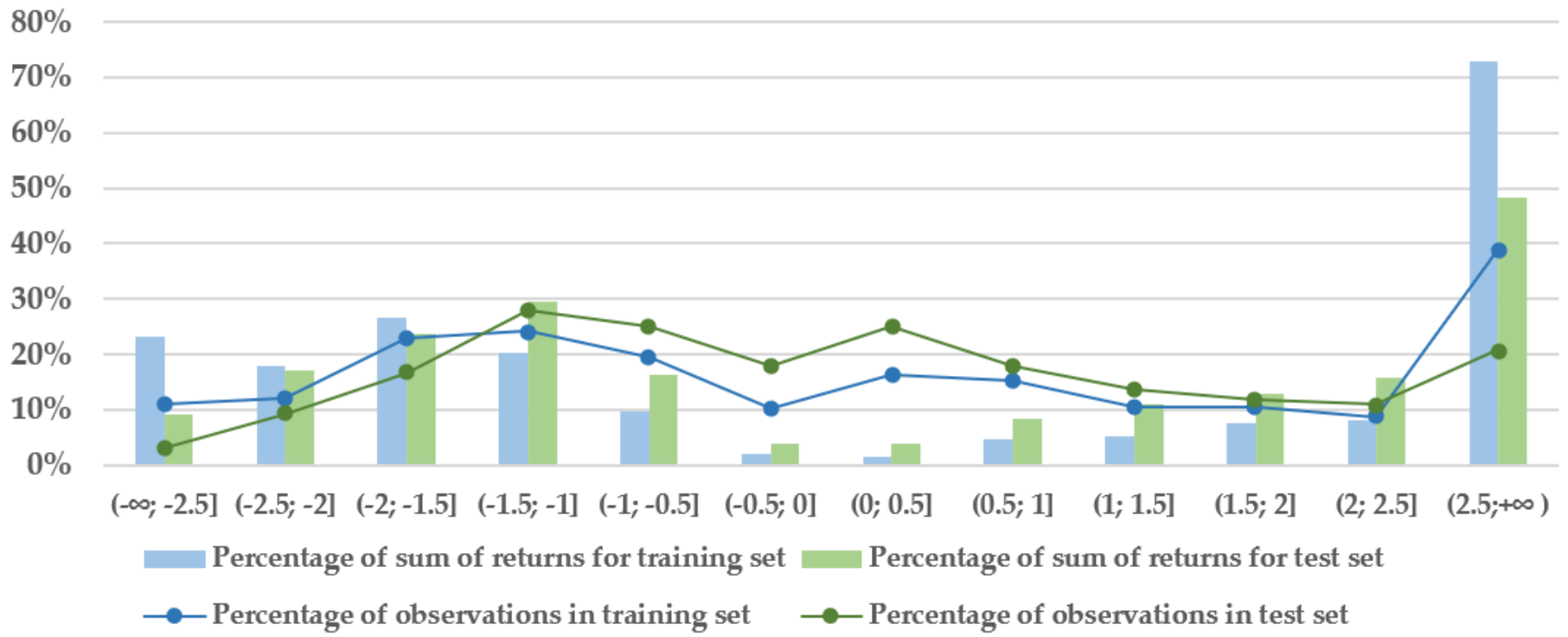

Figure 1. The number of positions and the level of returns (losses or profits) for various ranges of payoffs in the training and test sets.

Figures 2 and 3 present the values of $\operatorname{MPR}(\mathrm{x}), \mathrm{pMPR}(\mathrm{x})$ and $\mathrm{pNMPR}(\mathrm{x})$ indicators for the boundary values $(x \in\{0 ; 0.5 ; 1\})$ described above.

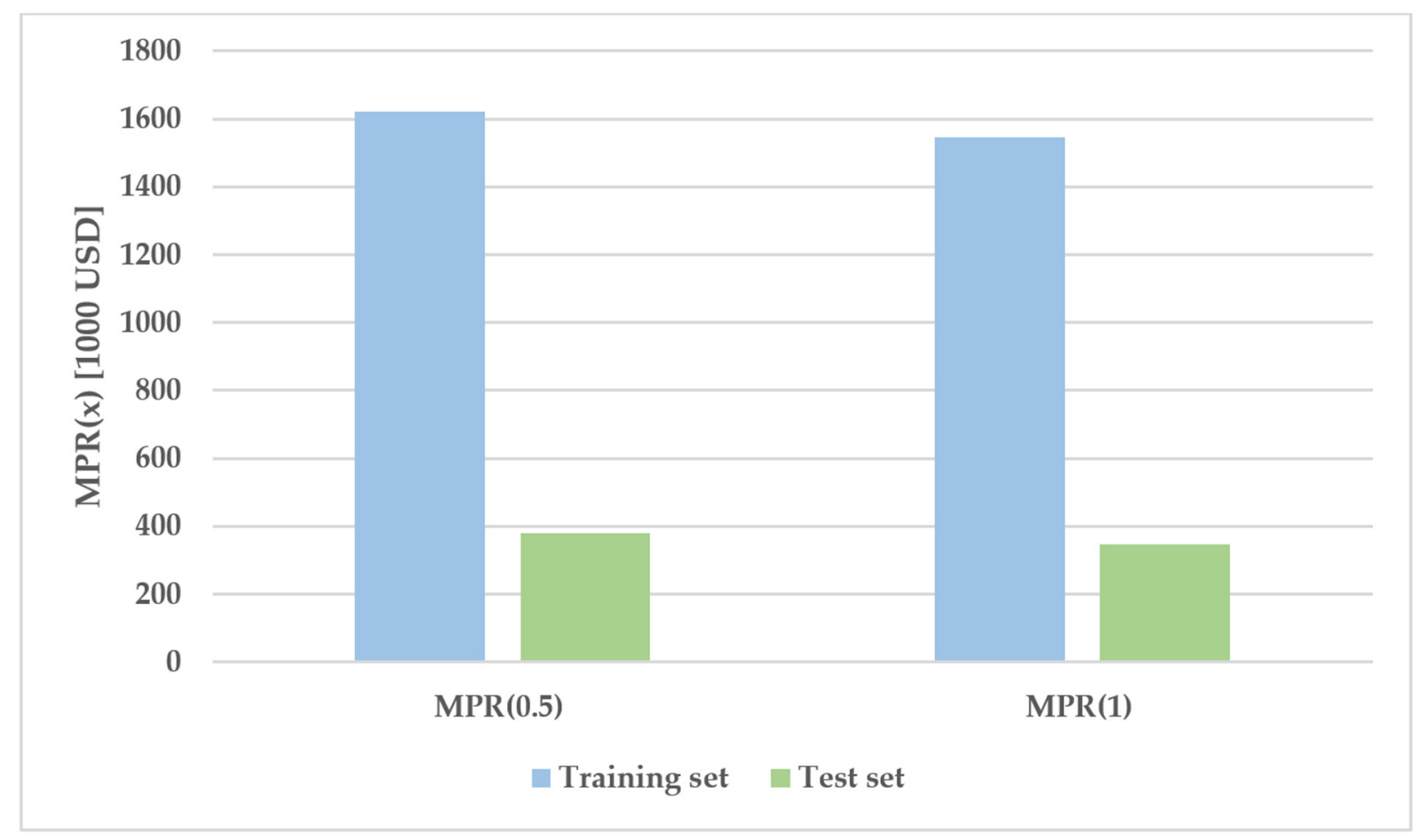

Figure 2. Values of indicators related to maximum returns from long call options for the training and test set.

In the case of the learning set, limiting buy signals to only options generating a minimum of USD 0.5 profit causes a relatively small decrease in maximum profit $\left(\mathrm{pMPR}_{(0)}{ }^{-}\right.$ $\operatorname{pMPR}_{(0.5)}=2 \%$; see Figure 3$)$. In the case of the test set, the change is twice as large and amounts to $4 \%$. For $\mathrm{pMPR}_{(0.5)}$ and $\mathrm{pMPR}_{(1)}$, the difference for the training set is $4 \%$ and $8 \%$ for the test set. The $\mathrm{pMPR}_{(1)}$ indicator for the test set drops to a level of $88 \%$, which is still a high level in relation to maximum profit (MP). 


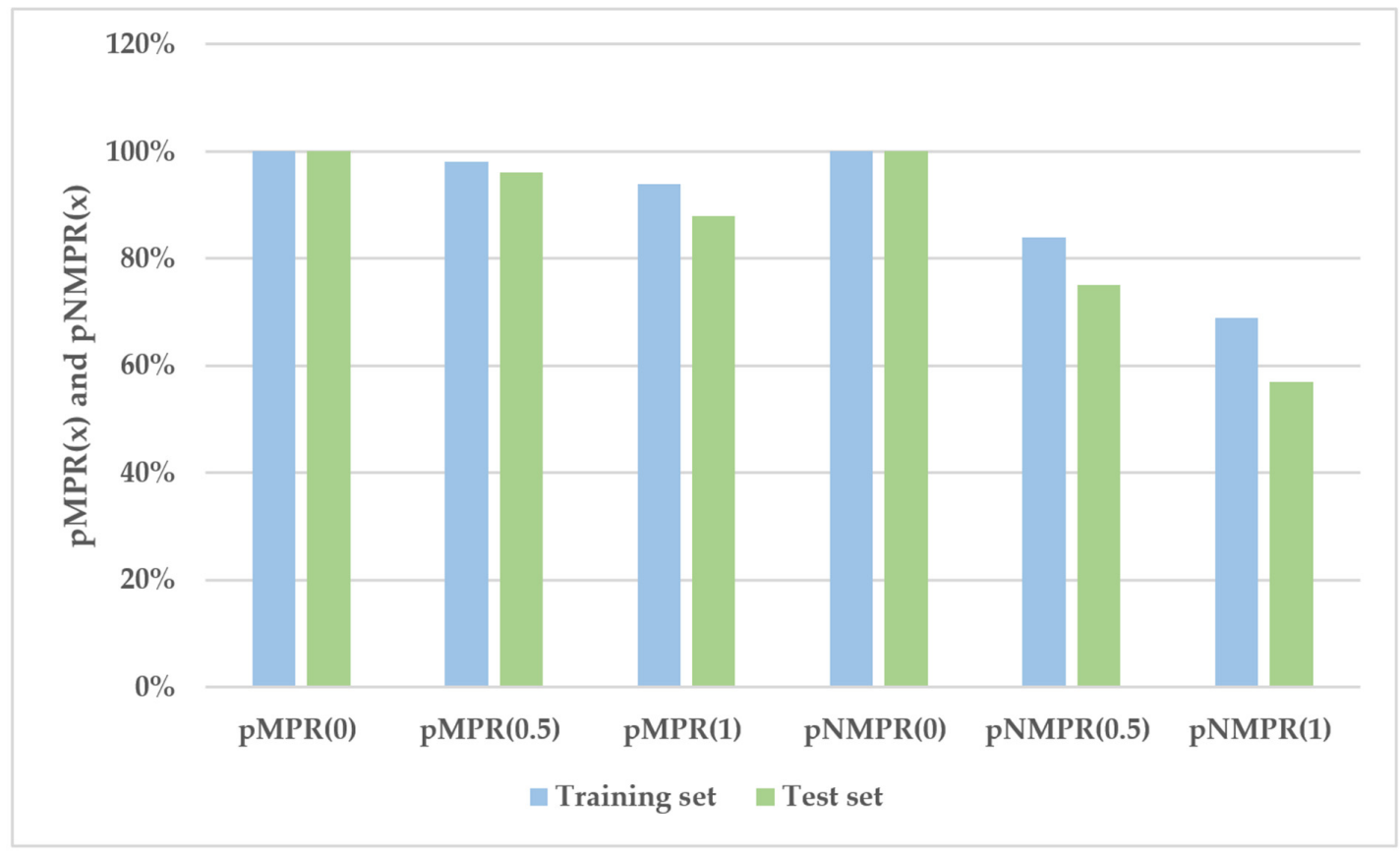

Figure 3. Percentage changes in indicators related to maximum returns from long call options for the training and test set.

In the case of the pNMPR indicator, the changes in subsequent intervals are much greater. As a result of shifting the threshold for generating buy signals from 0 to 0.5 , as many as $16 \%$ of observations from the training set stop generating buy signals. For the test set, this decrease is even greater reflecting as many as $1 / 4$ of all observations that make profits. If the boundary for generating buy signals is shifted to USD 1 , the number of observations that generate buy signals is reduced to $69 \%$ and $57 \%$, respectively. This means that for the training set, reducing the number of observations that generate buy signals by nearly $1 / 3$ (by changing the boundary from 0 to 1 ) translates into a reduction of the maximum level of profit by $6 \%$. For the test sample, a decrease in the number of observations generating a profit by $43 \%$ (the same change of the boundary as for the training set) translates into a reduction of maximum profit by $12 \%$.

The presented analysis shows that limiting observations generating buy signals for call options may significantly reduce the number of buy signals being generated, and thus increase the risk of not conducting a transaction that would potentially bring a profit and protect the company against the risk of a price increase. At the same time, the profit being generated in this way may not deteriorate markedly, as evidenced by changes in the value of pMPR.

\section{Results}

Input data for the ANNs reflected the state of the oil market at the time the decision to open a long position in a call option was to be made. The data consisted of the following:

- Nearest WTI futures prices, indicating current oil prices;

- Number of days until option expiry, which have a substantial impact on option premiums;

- Moving averages (arithmetic means) of $n$ recent settlement prices for WTI futures, where $n \in\{2,3, \ldots, 9,10,12,14, \ldots, 28,30,35,40, \ldots, 55,60\}$, signifying market trends;

- $\quad$ Standard deviations of $n$ recent WTI settlement prices for WTI futures, where $n \in\{1$, $2, \ldots, 9,10,12,14, \ldots, 28,30,35,40, \ldots, 55,60\}$ showing the dynamics of oil price changes.

In the next stage of empirical research, we use WTI oil futures prices to calculate two groups of indicators. The first group consists of standard deviations, which were estab- 
lished for $n$ recent settlement prices of the WTI futures, where $n \in\{1,2,3, \ldots, 9,10,12$, $14, \ldots, 28,30,35,40,45,50,55,60\}$. Therefore, 26 indicators were calculated for these values of $n$. The second group are arithmetic means of. In this case, 25 arithmetic means were calculated.

The above indicators as well as the number of days remaining until option expiry and WTI nearest futures prices were used as input data for ANNs.

Next, we analyzed the impact of the following parameters on the results of the network (ANN):

- The number of neurons in the hidden layer: from 5 to 30;

- Activation functions in the hidden layer: linear, logistic, exponential, sine and hyperbolic tangent;

- Activation functions in the output layer: linear, logistic, exponential, sine, hyperbolic tangent and softmax (for the joint entropy error evaluation function).

In the figures and tables, we used the following abbreviated names for activation functions:

- $\quad$ Exp-exponential;

- HTan-hyperbolic tangent;

- Lin-linear;

- Log-logistic;

- Sin-sine;

- Smax-softmax.

Additionally, the sum of squares and joint entropy were used as network error functions. A total of 750,000 networks were taught and analyzed for this study-50,000 each for five different hidden layer activation function in all three classes.

As a result, 250,000 networks were trained for each of the three classes. It should be emphasized once again that these classes were distinguished based on the expected level of returns (payoff) from a single call option (see Section 3). Table A1 in Appendix A shows the best networks based on the value of $\operatorname{EPR}(x)$ for the training set. The data are based on a combination of three network attributes: class, hidden layer and output layer activation functions. The 30 best networks were selected for each class (based on the combinations of activation functions used in the hidden and output layers). Thus, a total of 90 networks are to be considered best for the training set (for a given combination of activation function and class). The remainder of the article focuses only on the networks that achieved the highest rates of return (the best of the best). Table 3 presents the five best networks for each class. The selected networks give results classifying them in the top five due to each of the three aforementioned network assessment indicators for the training set $\left(\mathrm{EPR}_{0}, \mathrm{EPR}_{0.5}\right.$ and $\left.\mathrm{EPR}_{1}\right)$.

Table 3. Networks with the best results based on the EPR $(x)$ indicator.

\begin{tabular}{|c|c|c|c|c|c|c|c|c|c|}
\hline \multirow{2}{*}{ Number } & \multirow{2}{*}{ Class } & \multicolumn{2}{|c|}{ Activation Function } & \multicolumn{3}{|c|}{ Training Set } & \multicolumn{3}{|c|}{ Test Set } \\
\hline & & Hidden Layer & Output Layer & $\mathrm{EPR}_{0}$ & $\mathrm{EPR}_{0.5}$ & $\mathrm{EPR}_{1}$ & $\mathrm{EPR}_{0}$ & $\mathrm{EPR}_{0.5}$ & $\mathrm{EPR}_{1}$ \\
\hline 8 & \multirow{6}{*}{ I } & $\log$ & $\log$ & 1085.0 & 1070.5 & 1022.5 & 69.6 & 63.3 & 49.1 \\
\hline $10 *$ & & Log & Smax & 1175.2 & 1158.0 & 1100.2 & 67.8 & 63.0 & 57.2 \\
\hline $20 *$ & & HTan & $\log$ & 1135.7 & 1121.8 & 1072.5 & 63.0 & 57.2 & 45.7 \\
\hline 22 & & HTan & Smax & 1087.4 & 1070.0 & 1009.5 & 95.6 & 90.2 & 83.1 \\
\hline 28 & & Exp & Smax & 847.0 & 838.1 & 804.3 & 45.7 & 44.1 & 40.8 \\
\hline 39 & & Log & $\operatorname{Sin}$ & 556.3 & 553.9 & 535.2 & 47.5 & 47.0 & 47.0 \\
\hline 41 & \multirow{4}{*}{ II } & Log & HTan & 548.4 & 546.9 & 522.9 & 57.0 & 57.0 & 57.0 \\
\hline 52 & & HTan & Smax & 566.8 & 564.0 & 539.1 & 61.1 & 61.1 & 59.1 \\
\hline $53 *$ & & HTan & HTan & 569.5 & 567.4 & 551.8 & 58.4 & 58.3 & 58.3 \\
\hline $58 *$ & & $\operatorname{Exp}$ & Smax & 609.6 & 607.6 & 572.0 & 47.0 & 46.4 & 44.7 \\
\hline 71 & \multirow{5}{*}{ III } & Log & HTan & 537.2 & 536.2 & 531.4 & 53.0 & 52.6 & 52.6 \\
\hline 72 & & Log & Exp & 558.7 & 557.4 & 552.7 & 51.9 & 51.9 & 51.9 \\
\hline $80 *$ & & HTan & Log & 618.9 & 615.6 & 609.8 & 94.2 & 93.0 & 92.2 \\
\hline $82 *$ & & HTan & Smax & 676.7 & 675.5 & 671.4 & 105.3 & 104.4 & 103.7 \\
\hline 88 & & Exp & Smax & 561.9 & 560.4 & 554.0 & 45.6 & 45.6 & 45.6 \\
\hline
\end{tabular}

* The best two networks for each class are bold; 10 and 20-class I; 53 and 58-class II; 80 and 82-class III. 
In further analyses, the authors decided to focus on the two best results for the sample training sets in each class. For all classes and all indicators being considered $\left(\mathrm{EPR}_{0}, \mathrm{EPR}_{0.5}\right.$ and $E P R_{1}$ ), the best pair of networks dominated the results of the remaining networks. The results of the top five networks for a given class are included to provide a benchmark for further analysis, and the best two for each class of network are marked in bold with a * symbol in Table 3. The best pairs of networks are numbered: 10 and 20 (class I), 53 and 58 (class II), 80 and 82 (class III), respectively. The best results for the training sample for all three indicators were obtained for class I. The values of the analyzed indicators for the best class I networks are definitely higher (almost by a factor of 2) than the values of networks from the other classes. Interestingly, despite similar results in the training set for classes II and III, class III networks gave better results than class II networks. These observations seem not to be obvious based on $\operatorname{MPR}(\mathrm{x})$ values for each class (see: Section 3, Figure 3). When analyzing the results obtained for the test sample, it is worth noting that the values of the $\mathrm{EPR}_{0}$ indicator for networks in class I are significantly higher than the values of this indicator obtained by networks in class II. The advantage of networks from class I begins to decrease for subsequent indicators and for the EPR ${ }_{1}$ indicator one may conclude that the results obtained in both classes are comparable. The results obtained by networks from class III are particularly noteworthy-the results are clearly better than the best results obtained by networks from the other classes. Based on the EPR 1 indicator, the results for class III are almost twice as good as the results obtained for the other classes. These observations are illustrated in Figure 4.

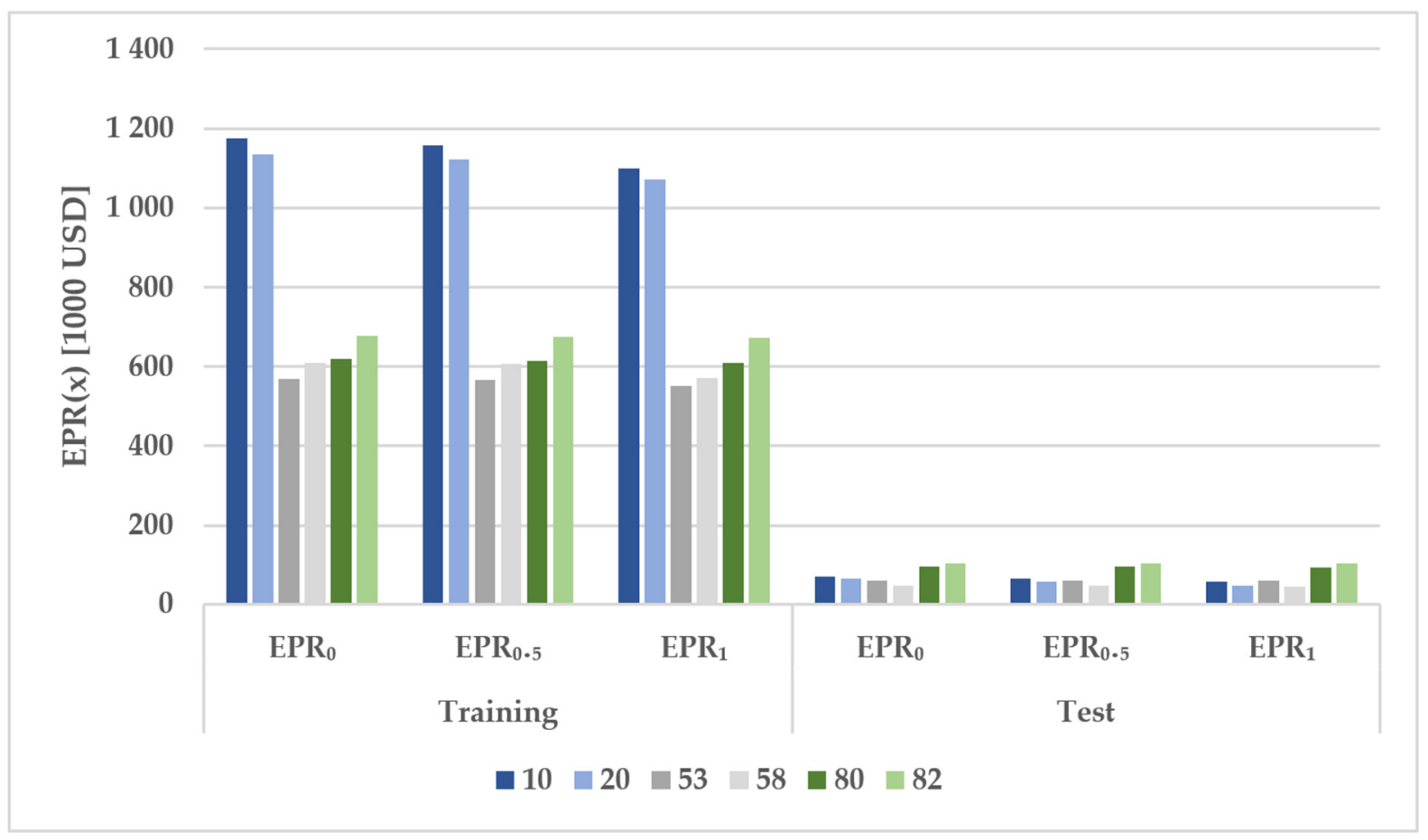

Figure 4. EPR indicator for the best pair of networks from each class.

Figure 4 clearly shows the dominance of class I networks for the training sample (networks 10 and 20, in blue) and the dominance of networks from class III for the test sample (networks 80 and 82, in green). The clear leader in the test set is network 82 from class III with a hyperbolic tangent activation function in the hidden layer and softmax activation function in the output layer.

One of the expected effects of the presented division into classes should be a decreasing drop in the values of $\operatorname{EPR}(\mathrm{x})$ indicators for the training set, along with an increase in risk appetite. Table 4 presents changes in the values of $\mathrm{EPR}_{0.5}$ and $\mathrm{EPR}_{1}$ indicators in relation to the value of $\mathrm{EPR}_{0}$. Networks presented in Table 3 were selected for comparison. Since 
in class I, buy signals were generated for all buy options for which payoff was positive, the values of $\mathrm{EPR}_{0.5}$ and $\mathrm{EPR}_{1}$ indicators may (but do not have to) drop significantly in relation to the value of $\mathrm{EPR}_{0}$. In the case of class II, a small difference between EPR 0.5 and $\mathrm{EPR}_{0}$ would be expected. However, for class III, for which buy signals should be generated for payoffs above USD 1, a slight decrease in value between $\mathrm{EPR}_{1}$ and $\mathrm{EPR}_{0}$ would be expected. This would mean that cases which generated a profit of less than USD 0.5 and 1 , respectively, would only have a small part of the generated profit.

Table 4. The difference in the values of the $\operatorname{EPR}(x)$ indicator for classes defined according to risk appetite.

\begin{tabular}{|c|c|c|c|c|c|c|c|}
\hline \multirow[b]{2}{*}{ Number } & \multirow[b]{2}{*}{ Class } & \multicolumn{2}{|c|}{ Activation Function } & \multicolumn{2}{|c|}{ Training Set } & \multicolumn{2}{|c|}{ Test Set } \\
\hline & & $\begin{array}{c}\text { Hidden } \\
\text { Layer }\end{array}$ & $\begin{array}{c}\text { Output } \\
\text { Layer }\end{array}$ & $\mathrm{EPR}_{0.5}-\mathrm{EPR}_{0}$ & $\mathrm{EPR}_{\mathbf{1}}-\mathrm{EPR}_{\mathbf{0}}$ & $\mathrm{EPR}_{0.5}-\mathrm{EPR}_{0}$ & $\mathrm{EPR}_{1}-\mathrm{EPR}_{0}$ \\
\hline 8 & & $\log$ & $\log$ & -14.5 & -62.5 & -6.3 & -20.5 \\
\hline $10 *$ & & Log & Smax & -17.3 & -75.0 & -4.8 & -10.5 \\
\hline 20 & I & HTan & $\log$ & -13.9 & -63.2 & -5.8 & $-\mathbf{1 7 . 3}$ \\
\hline 22 & & HTan & Smax & -17.5 & -77.9 & -5.3 & -12.5 \\
\hline 28 & & Exp & Smax & -8.9 & -42.7 & -1.6 & -4.9 \\
\hline 39 & & $\log$ & $\operatorname{Sin}$ & -2.5 & -21.1 & -0.5 & -0.5 \\
\hline 41 & & Log & HTan & -1.5 & -24.0 & 0.0 & 0.0 \\
\hline 52 & II & HTan & Smax & -2.9 & -27.8 & 0.0 & -1.9 \\
\hline $53 *$ & & HTan & HTan & -2.1 & $-\mathbf{1 7 . 7}$ & 0.0 & 0.0 \\
\hline $58 *$ & & Exp & Smax & -2.0 & -37.6 & -0.6 & -2.2 \\
\hline 71 & & Log & HTan & -1.0 & -5.8 & -0.4 & -0.4 \\
\hline 72 & & Log & Exp & -1.3 & -5.9 & 0.0 & 0.0 \\
\hline $80 *$ & III & HTan & Log & -3.3 & -9.1 & -1.2 & -1.9 \\
\hline 82 * & & HTan & Smax & -1.2 & -5.3 & -1.0 & -1.6 \\
\hline 88 & & Exp & Smax & -1.5 & -7.8 & 0.0 & 0.0 \\
\hline
\end{tabular}

* The best two networks for each class are bold.

Data presented in Table 4 confirms expectations regarding the magnitude of decreases for individual indicators-the largest decreases in successive values of $\operatorname{EPR}(\mathrm{x})$ for the training sample can be observed for class I. For class II, slight differences are visible between the values of $\mathrm{EPR}_{0.5}$ and $\mathrm{EPR}_{0}$, while for class III, the smallest difference is that between the values of EPR ${ }_{1}$ and $\mathrm{EPR}_{0}$. Based on the presented analysis of results, it can be concluded that the classification of observations based on the level of risk appetite strongly influences the choice of days for which a buy signal is generated. These are shown in Figure 5.

In the case of the test set, similar to the training set, distinctive values of differences in analyzed indicators can be observed only for networks in class I. For classes II and III, the differences in the value of $\operatorname{EPR}(\mathrm{x})$ indicators are very small.

In order to compare the presented values of EPR $(x)$ indicators obtained for individual networks with maximum returns that were generated in each class from long positions in call options, Table 5 presents the values of the \%MPR(x) indicator. The same networks were selected for the compilation that were the subject of previous analyses, i.e., the networks that gave the best results in individual classes based on the value of the $\operatorname{EPR}(\mathrm{x})$ indicator. A more detailed summary of the results is presented in the Appendix A in the Table A2. 


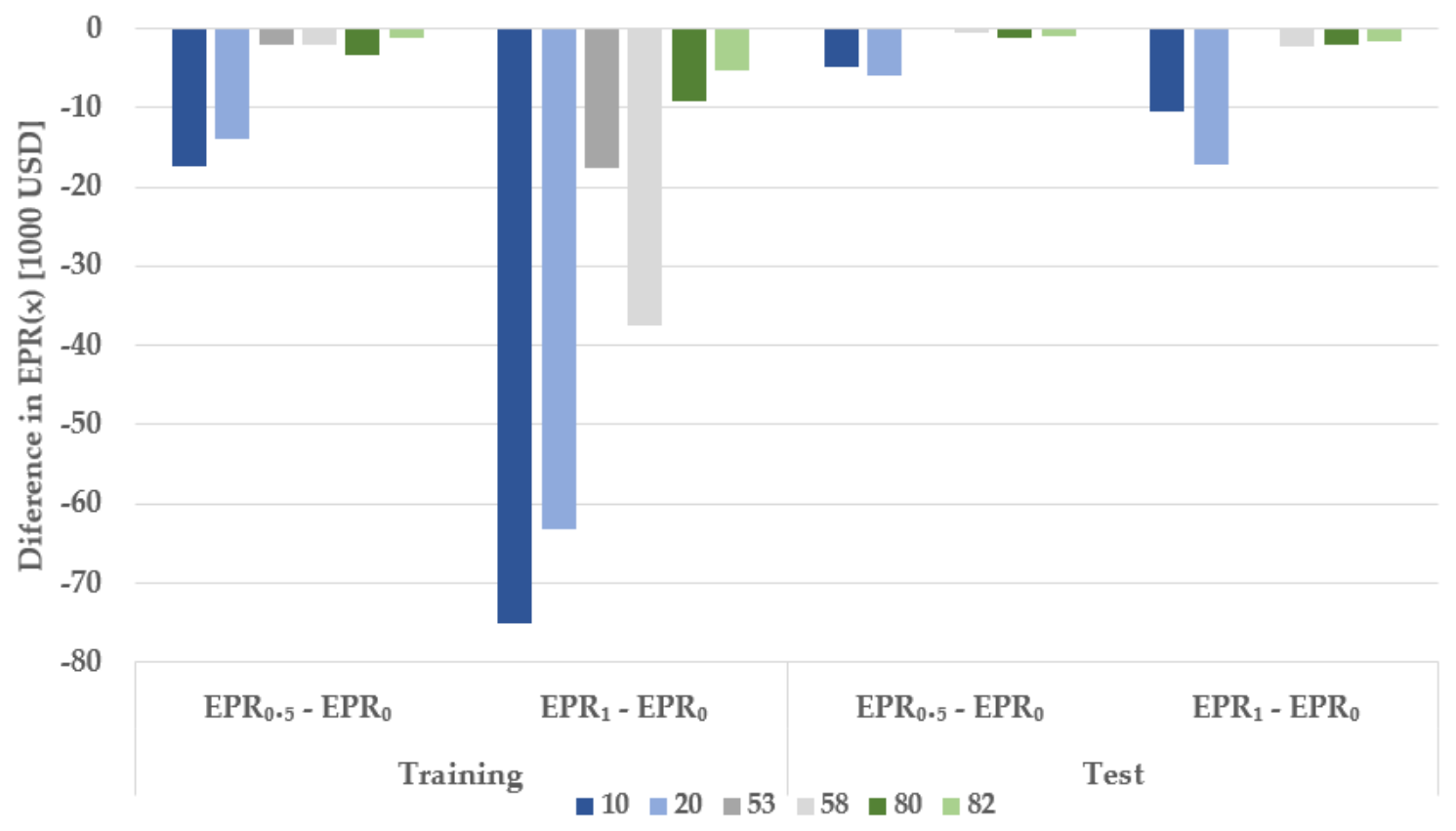

Figure 5. The difference in the value of $\operatorname{EPR}(x)$ for classes defined according to risk appetite.

Table 5. Networks with the best results of \%MPR(x) indicator.

\begin{tabular}{|c|c|c|c|c|c|c|c|c|c|}
\hline \multirow[b]{2}{*}{ Number } & \multirow[b]{2}{*}{ Class } & \multicolumn{2}{|c|}{ Activation Function } & \multicolumn{3}{|c|}{ Training Set } & \multicolumn{3}{|c|}{ Test Set } \\
\hline & & $\begin{array}{l}\text { Hidden } \\
\text { Layer }\end{array}$ & $\begin{array}{l}\text { Output } \\
\text { Layer }\end{array}$ & $\% \mathrm{MPR}_{0}$ & $\% \mathrm{MPR}_{0.5}$ & $\% \mathrm{MPR}_{1}$ & $\% \mathrm{MPR}_{0}$ & $\% \mathrm{MPR}_{0.5}$ & $\% \mathrm{MPR}_{1}$ \\
\hline 8 & \multirow{5}{*}{ I } & $\log$ & $\log$ & $65.9 \%$ & $66.0 \%$ & $66.2 \%$ & $17.6 \%$ & $16.6 \%$ & $14.2 \%$ \\
\hline $10 *$ & & Log & Smax & $71.4 \%$ & $71.4 \%$ & $71.2 \%$ & $17.1 \%$ & $16.6 \%$ & $16.5 \%$ \\
\hline $20 *$ & & HTan & Log & $69.0 \%$ & $69.2 \%$ & $69.4 \%$ & $15.9 \%$ & $15.0 \%$ & $13.2 \%$ \\
\hline 22 & & HTan & Smax & $66.0 \%$ & $66.0 \%$ & $65.3 \%$ & $24.2 \%$ & $23.7 \%$ & $23.9 \%$ \\
\hline 28 & & Exp & Smax & $51.4 \%$ & $51.7 \%$ & $52.1 \%$ & $11.5 \%$ & $11.6 \%$ & $11.8 \%$ \\
\hline 39 & \multirow{5}{*}{ II } & Log & Sin & $33.8 \%$ & $34.2 \%$ & $34.6 \%$ & $12.0 \%$ & $12.4 \%$ & $13.5 \%$ \\
\hline 41 & & Log & HTan & $33.3 \%$ & $33.7 \%$ & $33.8 \%$ & $14.4 \%$ & $15.0 \%$ & $16.4 \%$ \\
\hline 52 & & HTan & Smax & $34.4 \%$ & $34.8 \%$ & $34.9 \%$ & $15.4 \%$ & $16.0 \%$ & $17.0 \%$ \\
\hline $53 *$ & & HTan & HTan & $34.6 \%$ & $35.0 \%$ & $35.7 \%$ & $14.8 \%$ & $15.3 \%$ & $16.8 \%$ \\
\hline $58 *$ & & $\operatorname{Exp}$ & Smax & $37.0 \%$ & $37.5 \%$ & $37.0 \%$ & $11.9 \%$ & $12.2 \%$ & $12.9 \%$ \\
\hline 71 & \multirow{5}{*}{ III } & Log & HTan & $32.6 \%$ & $33.1 \%$ & $34.4 \%$ & $13.4 \%$ & $13.8 \%$ & $15.2 \%$ \\
\hline 72 & & Log & Exp & $33.9 \%$ & $34.4 \%$ & $35.8 \%$ & $13.1 \%$ & $13.6 \%$ & $15.0 \%$ \\
\hline 80 * & & HTan & Log & $37.6 \%$ & $38.0 \%$ & $39.5 \%$ & $23.8 \%$ & $24.5 \%$ & $26.6 \%$ \\
\hline $82 *$ & & HTan & Smax & $41.1 \%$ & $41.7 \%$ & $43.5 \%$ & $26.6 \%$ & $27.4 \%$ & $29.9 \%$ \\
\hline 88 & & Exp & Smax & $34.1 \%$ & $34.6 \%$ & $35.9 \%$ & $11.5 \%$ & $12.0 \%$ & $13.1 \%$ \\
\hline
\end{tabular}

* The best two networks for each class are bold.

The most interesting aspect of the presented compilation is the behavior of the $\% \operatorname{MPR}(\mathrm{x})$ indicator for the test set. For networks from classes II and III, there is a clear tendency of improvement in subsequent values of this indicator. It follows that networks of these classes are much better at predicting higher returns (i.e., those above USD 0.5 and 1). This observation is illustrated in Figure 6, which shows the best two networks from each class. 


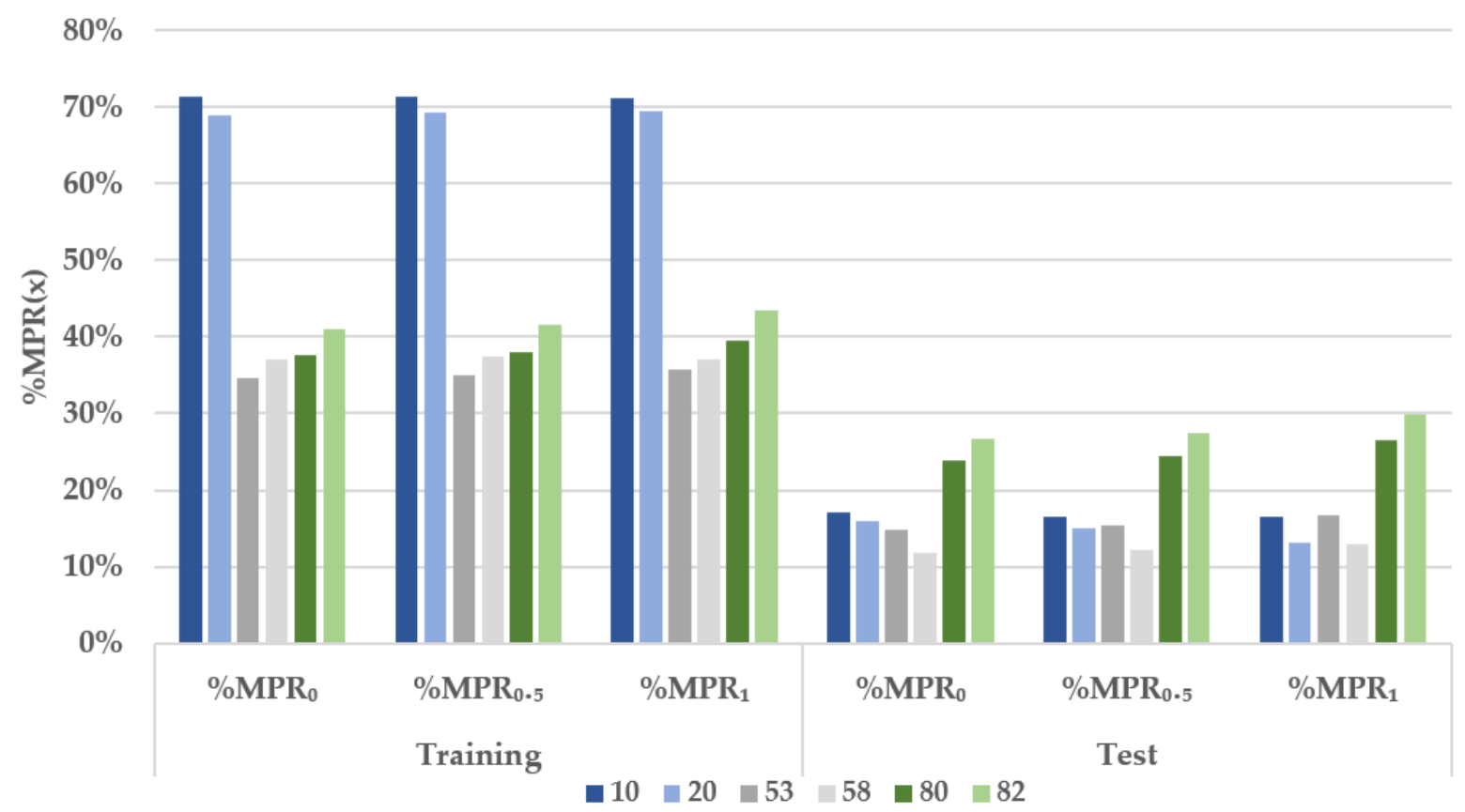

Figure 6. Values of the \%MPR(x) indicator for the pair of best networks for each class.

The last important aspect of the analyses that were carried out is the number of transactions-for this purpose, the pNEP indicator was used. Table 6 presents the values of $\mathrm{pNEP}$ for the analyzed networks. More detailed results are included in the Appendix A in Table A3.

Table 6. The value of the pNEP indicator for the set of analyzed networks.

\begin{tabular}{|c|c|c|c|c|c|}
\hline \multirow{2}{*}{ Number } & \multirow{2}{*}{ Class } & \multicolumn{2}{|c|}{ Activation Function } & \multirow{2}{*}{$\begin{array}{c}\text { Training } \\
\text { pNEP }\end{array}$} & \multirow{2}{*}{$\begin{array}{c}\text { Test } \\
\text { pNEP }\end{array}$} \\
\hline & & Hidden Layer & Output Layer & & \\
\hline 8 & & $\log$ & $\log$ & $24.9 \%$ & $28.5 \%$ \\
\hline $10 *$ & & Log & Smax & $32.3 \%$ & $18.2 \%$ \\
\hline $20 *$ & 1 & HTan & $\log$ & $24.9 \%$ & $24.1 \%$ \\
\hline 22 & & HTan & Smax & $33.1 \%$ & $20.5 \%$ \\
\hline 28 & & Exp & Smax & $22.3 \%$ & $11.9 \%$ \\
\hline 39 & & $\log$ & $\operatorname{Sin}$ & $16.4 \%$ & $4.7 \%$ \\
\hline 41 & & $\log$ & HTan & $15.8 \%$ & $3.5 \%$ \\
\hline 52 & 2 & HTan & Smax & $18.8 \%$ & $5.6 \%$ \\
\hline $53 *$ & & HTan & HTan & $15.6 \%$ & $3.5 \%$ \\
\hline $58 *$ & & $\operatorname{Exp}$ & Smax & $15.9 \%$ & $3.2 \%$ \\
\hline 71 & & $\log$ & HTan & $11.2 \%$ & $4.4 \%$ \\
\hline 72 & & Log & Exp & $9.4 \%$ & $2.7 \%$ \\
\hline $80 *$ & 3 & HTan & Log & $13.9 \%$ & $7.2 \%$ \\
\hline $82 *$ & & HTan & Smax & $10.8 \%$ & $8.9 \%$ \\
\hline 88 & & Exp & Smax & $12.5 \%$ & $2.1 \%$ \\
\hline
\end{tabular}

* The best two networks for each class are bold.

Class I networks had by far the highest values of the pNEP indicator (for both the training and test samples). As expected, for the learning sample, the lowest value of the pNEP indicator is for networks from class III. The results for the training sample presented in Table 6 are in line with the expectations based on data analysis (see Figure 3). However, it is worth noting the values of the pNEP indicator for the test sample-for networks in class II, the value of this indicator for the best networks are significantly lower than the value of pNEP for the best class III networks. On the other hand, the best class II networks (despite several lower pNEP indicator values compared to the best class I networks) generated only slightly lower values of the $\operatorname{EPR}(\mathrm{x})$ and \%MPR $(\mathrm{x})$ indicators. At the same time, the lower 
number of long call options positions generated is associated with a potentially higher risk of not taking a position in the event of large fluctuations in the oil price. Hence, class II networks are dedicated to enterprises with an average level of risk appetite. Additionally noteworthy are the relatively high levels of the pNEP indicator for class III networks. Comparing these results with the \%MPR(x) indicator, it can be clearly stated that networks of this class are characterized by a high degree of accuracy in generating buy signals for observations with a positive payoff, with particular emphasis on observations with a payoff value exceeding USD 1.

\section{Conclusions and Future Research Directions}

Results from the authors' previous studies $[48,49]$ were confirmed that indiscriminate purchasing of options, specifically buying a call option every day, for hedging against oil price risk results in a loss for all scenarios in the data: both training and test sets, over the 10 -year period under analysis. Thus, a more sophisticated approach is required, and the methodology presented in the aforementioned studies resulted in both price risk protection and increased profits for both the training and test sets. This article proposes a completely new approach to the problem of hedging against the risk of oil price increases, in which the decision to purchase a call option (or not) was made using ANNs, which were trained taking into account the hedger's risk appetite. For the purpose of this article, risk appetite was defined as the propensity of an enterprise to refrain from hedging if potential gains from purchasing an option (payoff) are below a set value. The consequence of this approach is a lower number of transactions concluded on the commodity options market, and hence an increased probability of less protection in the event of large fluctuations in oil prices.

The authors analyzed three classes of networks, each corresponding to a company's willingness to take risk resulting from fluctuations in WTI crude oil prices. Results confirmed that the number of transactions concluded (both for the training and testing set) grew with decreasing risk appetite. However, this had a relatively small impact on total returns for a given network class. The networks generating the highest returns in the test set were those with the highest level of risk appetite. This conclusion is important from the point of view of further analyses of the possibility of hedging against the risk of commodity price fluctuations (including oil prices) using ANNs. The obtained results allow us to look at the problem of classifying options in terms of generating buy signals from a completely different perspective.

The strategy presented in this study lets businesses modify this approach by adopting a strategy that reflects their risk appetite. Significantly, in this study, we showed that increased risk appetite, by targeting higher ranges of profits in ANNs, can improve profits in hedging against oil price risk.

In future research, we will test additional learning algorithms and modify the strategy to account for specific real-life scenarios, such as the desire to hedge against oil price risk for a specific amount of oil to be purchased over a given period. This adds significant complexity in determining not only whether to buy a call option on a given day but also varying the number of options to be purchased. This has a significant impact on both risk and profit profiles.

Author Contributions: Conceptualization, R.P., B.Ł., M.M.; model design and model calculations, R.P., B.Ł., M.M.; writing—original draft preparation, R.P., B.Ł., M.M.; data visualization, R.P., B.Ł., M.M.; discussion, R.P., B.t., M.M.; writing—review and editing, R.P., B.Ł., M.M. All authors have read and agreed to the published version of the manuscript.

Funding: The APC was funded under subvention funds for the Faculty of Management and by program "Excellence Initiative-Research University" for the AGH University of Science and Technology.

Institutional Review Board Statement: Not applicable.

Informed Consent Statement: Not applicable. 
Data Availability Statement: Data from this study are available upon request. The volume of collected data is very large thus it was impractical to present it all here.

Conflicts of Interest: The authors declare no conflict of interest.

\section{Nomenclature}

$\begin{array}{ll}\text { ANN } & \text { artificial neural networks } \\ \text { AR } & \text { average return } \\ \text { ATM } & \text { at-the-money } \\ \text { BPNN } & \text { backpropagation neural network } \\ \text { CL } & \text { WTI Light Sweet Crude Oil future contract } \\ \text { EP } & \text { expected profit } \\ \text { ERNN } & \text { Elman recurrent neural networks } \\ \text { FR } & \text { fuzzy regression } \\ \text { GA-NN } & \text { genetic algorithm and neural network } \\ \text { MAPE } & \text { mean absolute percentage error } \\ \text { MP } & \text { maximum profit } \\ \text { NYMEX } & \text { New York Mercantile Exchange } \\ \text { ST } & \text { stochastic time effective function } \\ \text { WTI } & \text { West Texas Intermediate }\end{array}$

\section{Appendix A}

Table A1. Networks with the best results based on the EPR $(x)$ indicator.

\begin{tabular}{|c|c|c|c|c|c|c|c|c|c|}
\hline \multirow{2}{*}{ Number } & \multirow{2}{*}{ Class } & \multicolumn{2}{|c|}{ Activation Function } & \multicolumn{3}{|c|}{ Training Set } & \multicolumn{3}{|c|}{ Test Set } \\
\hline & & Hidden Layer & Output Layer & EP & $\mathrm{EP}_{0.5}$ & $\mathbf{E P}_{1}$ & EP & $\mathbf{E P}_{0.5}$ & $\mathbf{E P}_{1}$ \\
\hline 1 & \multirow{30}{*}{1} & \multirow{7}{*}{ Lin } & Lin & 25.5 & 25.2 & 23.9 & 0.1 & -0.3 & -0.3 \\
\hline 2 & & & $\log$ & 27.8 & 27.4 & 26.1 & 0.5 & 0.0 & 0.0 \\
\hline 3 & & & Sin & 26.7 & 26.3 & 25.0 & 0.5 & 0.0 & 0.0 \\
\hline 4 & & & Smax & 31.2 & 30.1 & 25.6 & 14.6 & 14.1 & 14.1 \\
\hline 5 & & & HTan & 23.4 & 23.0 & 21.7 & 0.5 & 0.0 & 0.0 \\
\hline 6 & & & Exp & 29.8 & 29.7 & 26.8 & 15.2 & 14.9 & 14.9 \\
\hline 7 & & & Lin & 366.9 & 361.5 & 342.5 & 52.7 & 51.8 & 47.0 \\
\hline $8 *$ & & \multirow{5}{*}{$\log$} & Log & 1085.0 & 1070.5 & 1022.5 & 69.6 & 63.3 & 49.1 \\
\hline 9 & & & Sin & 410.0 & 404.9 & 383.6 & 70.2 & 68.2 & 59.1 \\
\hline $10 *$ & & & Smax & 1175.2 & 1158.0 & 1100.2 & 67.8 & 63.0 & 57.2 \\
\hline 11 & & & HTan & 361.4 & 359.1 & 347.1 & 33.1 & 32.9 & 32.9 \\
\hline 12 & & & Exp & 380.6 & 376.9 & 364.5 & 39.4 & 39.4 & 39.4 \\
\hline 13 & & \multirow{7}{*}{$\operatorname{Sin}$} & Lin & 143.4 & 143.0 & 138.8 & 47.1 & 47.1 & 47.1 \\
\hline 14 & & & $\log$ & 188.6 & 187.7 & 183.7 & 46.0 & 46.0 & 46.0 \\
\hline 15 & & & Sin & 149.0 & 148.1 & 144.8 & 37.6 & 37.5 & 37.5 \\
\hline 16 & & & Smax & 209.2 & 208.4 & 205.3 & 24.2 & 23.8 & 23.8 \\
\hline 17 & & & HTan & 215.0 & 213.9 & 209.1 & 50.2 & 50.1 & 50.1 \\
\hline 18 & & & Exp & 168.8 & 167.8 & 162.8 & 44.1 & 44.1 & 44.1 \\
\hline 19 & & & Lin & 378.9 & 375.0 & 353.5 & 45.7 & 42.2 & 33.7 \\
\hline $20 *$ & & \multirow{5}{*}{ HTan } & Log & 1135.7 & 1121.8 & 1072.5 & 63.0 & 57.2 & 45.7 \\
\hline 21 & & & Sin & 524.7 & 518.5 & 491.4 & 38.6 & 33.2 & 20.8 \\
\hline $22 *$ & & & Smax & 1087.4 & 1070.0 & 1009.5 & 95.6 & 90.2 & 83.1 \\
\hline 23 & & & HTan & 709.0 & 701.6 & 677.8 & 84.3 & 82.9 & 79.7 \\
\hline 24 & & & Exp & 533.1 & 527.2 & 507.1 & 44.3 & 44.3 & 44.3 \\
\hline 25 & & \multirow{6}{*}{ Exp } & Lin & 244.8 & 241.4 & 230.8 & 35.0 & 35.0 & 33.7 \\
\hline 26 & & & $\log$ & 719.7 & 709.3 & 675.3 & 70.5 & 69.7 & 68.1 \\
\hline 27 & & & Sin & 365.0 & 361.8 & 347.2 & 37.9 & 37.6 & 35.7 \\
\hline $28 *$ & & & Smax & 847.0 & 838.1 & 804.3 & 45.7 & 44.1 & 40.8 \\
\hline 29 & & & HTan & 298.2 & 294.7 & 282.0 & 45.2 & 45.2 & 45.2 \\
\hline 30 & & & Exp & 281.0 & 279.6 & 269.5 & 41.3 & 41.3 & 41.3 \\
\hline
\end{tabular}


Table A1. Cont.

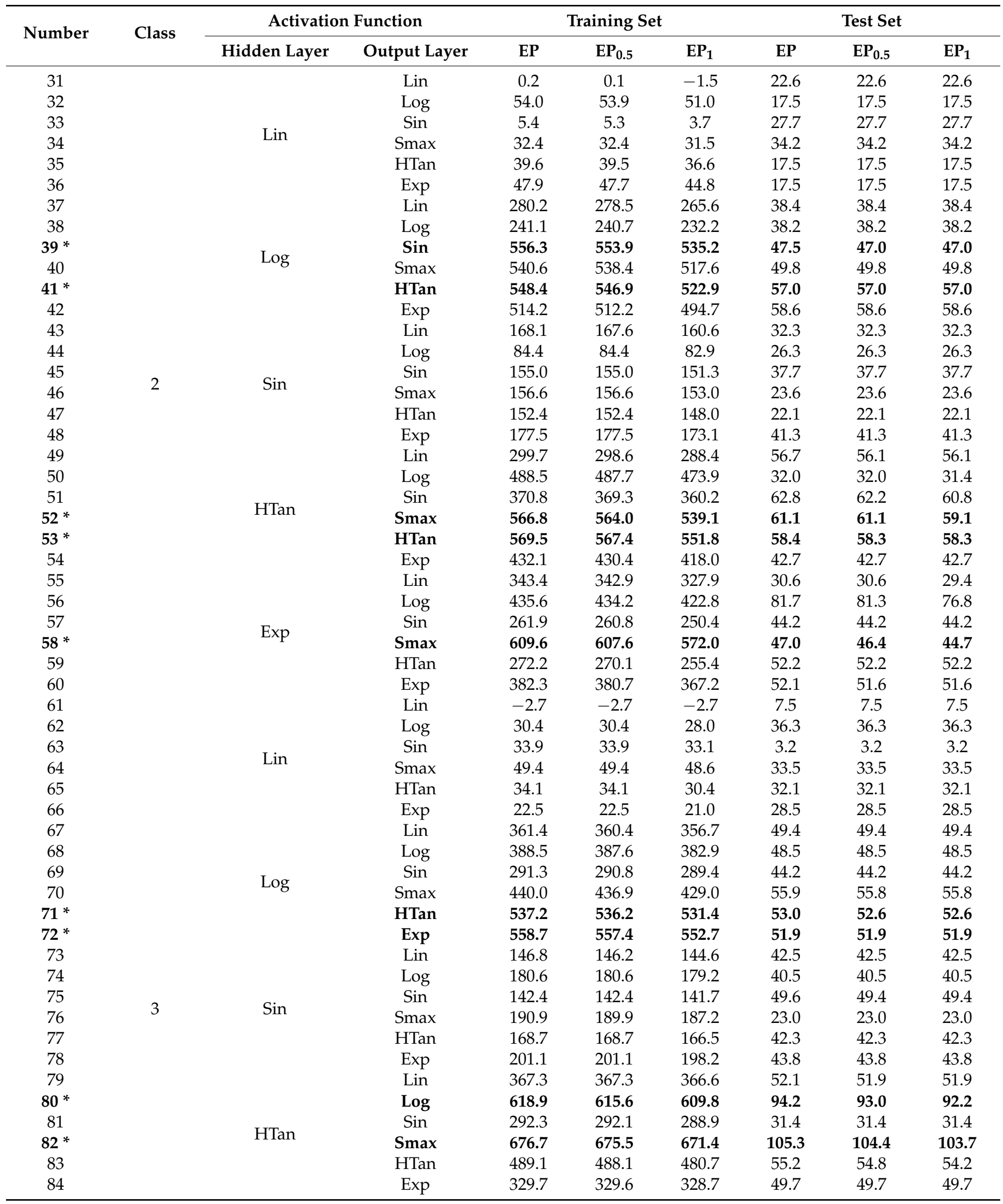


Table A1. Cont.

\begin{tabular}{|c|c|c|c|c|c|c|c|c|c|}
\hline \multirow{2}{*}{ Number } & \multirow{2}{*}{ Class } & \multicolumn{2}{|c|}{ Activation Function } & \multicolumn{3}{|c|}{ Training Set } & \multicolumn{3}{|c|}{ Test Set } \\
\hline & & Hidden Layer & Output Layer & EP & $\mathrm{EP}_{0.5}$ & $\mathbf{E P}_{1}$ & EP & $\mathrm{EP}_{0.5}$ & $\mathrm{EP}_{1}$ \\
\hline 85 & \multirow{6}{*}{3} & \multirow{6}{*}{ Exp } & Lin & 293.2 & 292.5 & 284.6 & 55.1 & 55.1 & 55.1 \\
\hline 86 & & & $\log$ & 288.7 & 288.2 & 286.5 & 54.4 & 54.4 & 54.4 \\
\hline 87 & & & Sin & 238.1 & 237.2 & 231.1 & 48.7 & 48.7 & 48.7 \\
\hline $88 *$ & & & Smax & 561.9 & 560.4 & 554.0 & 45.6 & 45.6 & 45.6 \\
\hline 89 & & & HTan & 333.9 & 333.7 & 328.3 & 57.9 & 57.4 & 57.4 \\
\hline 90 & & & Exp & 364.1 & 363.2 & 359.1 & 41.7 & 41.7 & 41.7 \\
\hline
\end{tabular}

* The best five networks for each class are bold.

Table A2. Networks with the best results of $\% \mathrm{MPR}(\mathrm{x})$ indicator.

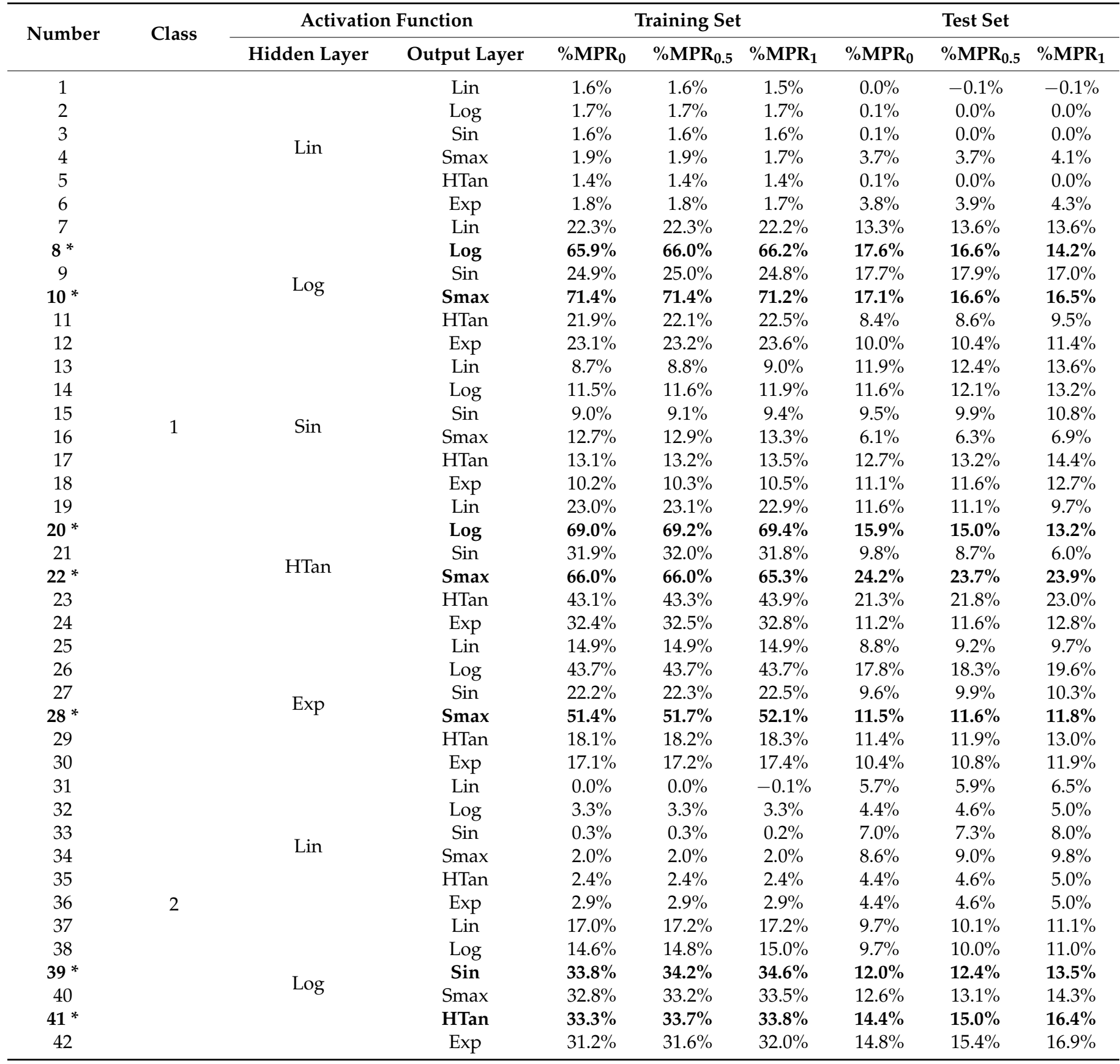


Table A2. Cont.

\begin{tabular}{|c|c|c|c|c|c|c|c|c|c|}
\hline \multirow{2}{*}{ Number } & \multirow{2}{*}{ Class } & \multicolumn{2}{|c|}{ Activation Function } & \multicolumn{3}{|c|}{ Training Set } & \multicolumn{3}{|c|}{ Test Set } \\
\hline & & Hidden Layer & Output Layer & $\% \mathrm{MPR}_{0}$ & $\% \mathrm{MPR}_{0.5}$ & $\% \mathrm{MPR}_{1}$ & $\% \mathrm{MPR}_{\mathbf{0}}$ & $\% \mathrm{MPR}_{0.5}$ & $\% \mathrm{MPR}_{1}$ \\
\hline 43 & \multirow{18}{*}{2} & \multirow{7}{*}{$\operatorname{Sin}$} & Lin & $10.2 \%$ & $10.3 \%$ & $10.4 \%$ & $8.2 \%$ & $8.5 \%$ & $9.3 \%$ \\
\hline 44 & & & $\log$ & $5.1 \%$ & $5.2 \%$ & $5.4 \%$ & $6.7 \%$ & $6.9 \%$ & $7.6 \%$ \\
\hline 45 & & & Sin & $9.4 \%$ & $9.6 \%$ & $9.8 \%$ & $9.5 \%$ & $9.9 \%$ & $10.9 \%$ \\
\hline 46 & & & Smax & $9.5 \%$ & $9.7 \%$ & $9.9 \%$ & $6.0 \%$ & $6.2 \%$ & $6.8 \%$ \\
\hline 47 & & & HTan & $9.3 \%$ & $9.4 \%$ & $9.6 \%$ & $5.6 \%$ & $5.8 \%$ & $6.4 \%$ \\
\hline 48 & & & Exp & $10.8 \%$ & $10.9 \%$ & $11.2 \%$ & $10.4 \%$ & $10.9 \%$ & $11.9 \%$ \\
\hline 49 & & & Lin & $18.2 \%$ & $18.4 \%$ & $18.7 \%$ & $14.3 \%$ & $14.7 \%$ & $16.2 \%$ \\
\hline 50 & & \multirow{5}{*}{ HTan } & $\log$ & $29.7 \%$ & $30.1 \%$ & $30.7 \%$ & $8.1 \%$ & $8.4 \%$ & $9.0 \%$ \\
\hline 51 & & & $\operatorname{Sin}$ & $22.5 \%$ & $22.8 \%$ & $23.3 \%$ & $15.9 \%$ & $16.4 \%$ & $17.5 \%$ \\
\hline $52 *$ & & & Smax & $34.4 \%$ & $34.8 \%$ & $34.9 \%$ & $15.4 \%$ & $16.0 \%$ & $17.0 \%$ \\
\hline $53 *$ & & & HTan & $34.6 \%$ & $35.0 \%$ & $35.7 \%$ & $14.8 \%$ & $15.3 \%$ & $16.8 \%$ \\
\hline 54 & & & Exp & $26.2 \%$ & $26.5 \%$ & $27.1 \%$ & $10.8 \%$ & $11.2 \%$ & $12.3 \%$ \\
\hline 55 & & \multirow{6}{*}{ Exp } & Lin & $20.9 \%$ & $21.1 \%$ & $21.2 \%$ & $7.7 \%$ & $8.1 \%$ & $8.5 \%$ \\
\hline 56 & & & Log & $26.5 \%$ & $26.8 \%$ & $27.4 \%$ & $20.7 \%$ & $21.4 \%$ & $22.1 \%$ \\
\hline 57 & & & $\operatorname{Sin}$ & $15.9 \%$ & $16.1 \%$ & $16.2 \%$ & $11.2 \%$ & $11.6 \%$ & $12.7 \%$ \\
\hline $58 *$ & & & Smax & $37.0 \%$ & $37.5 \%$ & $37.0 \%$ & $11.9 \%$ & $12.2 \%$ & $12.9 \%$ \\
\hline 59 & & & HTan & $16.5 \%$ & $16.7 \%$ & $16.5 \%$ & $13.2 \%$ & $13.7 \%$ & $15.0 \%$ \\
\hline 60 & & & Exp & $23.2 \%$ & $23.5 \%$ & $23.8 \%$ & $13.2 \%$ & $13.6 \%$ & $14.9 \%$ \\
\hline 61 & \multirow{30}{*}{3} & \multirow{6}{*}{ Lin } & Lin & $-0.2 \%$ & $-0.2 \%$ & $-0.2 \%$ & $1.9 \%$ & $2.0 \%$ & $2.2 \%$ \\
\hline 62 & & & Log & $1.8 \%$ & $1.9 \%$ & $1.8 \%$ & $9.2 \%$ & $9.5 \%$ & $10.5 \%$ \\
\hline 63 & & & Sin & $2.1 \%$ & $2.1 \%$ & $2.1 \%$ & $0.8 \%$ & $0.8 \%$ & $0.9 \%$ \\
\hline 64 & & & Smax & $3.0 \%$ & $3.0 \%$ & $3.1 \%$ & $8.5 \%$ & $8.8 \%$ & $9.6 \%$ \\
\hline 65 & & & HTan & $2.1 \%$ & $2.1 \%$ & $2.0 \%$ & $8.1 \%$ & $8.4 \%$ & $9.2 \%$ \\
\hline 66 & & & Exp & $1.4 \%$ & $1.4 \%$ & $1.4 \%$ & $7.2 \%$ & $7.5 \%$ & $8.2 \%$ \\
\hline 67 & & \multirow{6}{*}{$\log$} & Lin & $21.9 \%$ & $22.2 \%$ & $23.1 \%$ & $12.5 \%$ & $13.0 \%$ & $14.2 \%$ \\
\hline 68 & & & $\log$ & $23.6 \%$ & $23.9 \%$ & $24.8 \%$ & $12.3 \%$ & $12.8 \%$ & $14.0 \%$ \\
\hline 69 & & & Sin & $17.7 \%$ & $17.9 \%$ & $18.7 \%$ & $11.2 \%$ & $11.6 \%$ & $12.7 \%$ \\
\hline 70 & & & Smax & $26.7 \%$ & $26.9 \%$ & $27.8 \%$ & $14.1 \%$ & $14.7 \%$ & $16.1 \%$ \\
\hline $71 *$ & & & HTan & $32.6 \%$ & $33.1 \%$ & $34.4 \%$ & $13.4 \%$ & $13.8 \%$ & $15.2 \%$ \\
\hline $72 *$ & & & Exp & $33.9 \%$ & $34.4 \%$ & $35.8 \%$ & $13.1 \%$ & $13.6 \%$ & $15.0 \%$ \\
\hline 73 & & \multirow{7}{*}{ Sin } & Lin & $8.9 \%$ & $9.0 \%$ & $9.4 \%$ & $10.7 \%$ & $11.2 \%$ & $12.2 \%$ \\
\hline 74 & & & Log & $11.0 \%$ & $11.1 \%$ & $11.6 \%$ & $10.2 \%$ & $10.6 \%$ & $11.7 \%$ \\
\hline 75 & & & Sin & $8.6 \%$ & $8.8 \%$ & $9.2 \%$ & $12.5 \%$ & $13.0 \%$ & $14.2 \%$ \\
\hline 76 & & & Smax & $11.6 \%$ & $11.7 \%$ & $12.1 \%$ & $5.8 \%$ & $6.0 \%$ & $6.6 \%$ \\
\hline 77 & & & HTan & $10.2 \%$ & $10.4 \%$ & $10.8 \%$ & $10.7 \%$ & $11.1 \%$ & $12.2 \%$ \\
\hline 78 & & & Exp & $12.2 \%$ & $12.4 \%$ & $12.8 \%$ & $11.1 \%$ & $11.5 \%$ & $12.6 \%$ \\
\hline 79 & & & Lin & $22.3 \%$ & $22.7 \%$ & $23.7 \%$ & $13.2 \%$ & $13.6 \%$ & $14.9 \%$ \\
\hline $80 *$ & & \multirow{5}{*}{ HTan } & Log & $37.6 \%$ & $38.0 \%$ & $39.5 \%$ & $23.8 \%$ & $24.5 \%$ & $26.6 \%$ \\
\hline 81 & & & Sin & $17.7 \%$ & $18.0 \%$ & $18.7 \%$ & $7.9 \%$ & $8.2 \%$ & $9.0 \%$ \\
\hline $82 *$ & & & Smax & $41.1 \%$ & $41.7 \%$ & $43.5 \%$ & $26.6 \%$ & $27.4 \%$ & $29.9 \%$ \\
\hline 83 & & & HTan & $29.7 \%$ & $30.1 \%$ & $31.1 \%$ & $13.9 \%$ & $14.4 \%$ & $15.6 \%$ \\
\hline 84 & & & Exp & $20.0 \%$ & $20.3 \%$ & $21.3 \%$ & $12.6 \%$ & $13.1 \%$ & $14.3 \%$ \\
\hline 85 & & \multirow{6}{*}{ Exp } & Lin & $17.8 \%$ & $18.0 \%$ & $18.4 \%$ & $13.9 \%$ & $14.5 \%$ & $15.9 \%$ \\
\hline 86 & & & $\log$ & $17.5 \%$ & $17.8 \%$ & $18.5 \%$ & $13.8 \%$ & $14.3 \%$ & $15.7 \%$ \\
\hline 87 & & & Sin & $14.5 \%$ & $14.6 \%$ & $15.0 \%$ & $12.3 \%$ & $12.8 \%$ & $14.0 \%$ \\
\hline 88 * & & & Smax & $34.1 \%$ & $34.6 \%$ & $35.9 \%$ & $11.5 \%$ & $12.0 \%$ & $13.1 \%$ \\
\hline 89 & & & HTan & $20.3 \%$ & $20.6 \%$ & $21.2 \%$ & $14.6 \%$ & $15.1 \%$ & $16.5 \%$ \\
\hline 90 & & & Exp & $22.1 \%$ & $22.4 \%$ & $23.2 \%$ & $10.6 \%$ & $11.0 \%$ & $12.0 \%$ \\
\hline
\end{tabular}

* The best five networks for each class are bold. 
Table A3. The value of the pNEP indicator for the set of analyzed networks.

\begin{tabular}{|c|c|c|c|c|c|}
\hline \multirow{2}{*}{ Number } & \multirow{2}{*}{ Class } & \multicolumn{2}{|c|}{ Activation Function } & \multirow{2}{*}{$\begin{array}{c}\text { Training Set } \\
\text { pNEP }\end{array}$} & \multirow{2}{*}{$\begin{array}{c}\text { Test Set } \\
\text { pNEP }\end{array}$} \\
\hline & & Hidden Layer & Output Layer & & \\
\hline 1 & \multirow{28}{*}{1} & \multirow{7}{*}{ Lin } & Lin & $2.3 \%$ & $0.6 \%$ \\
\hline 2 & & & $\log$ & $1.9 \%$ & $0.3 \%$ \\
\hline 3 & & & $\operatorname{Sin}$ & $1.9 \%$ & $0.3 \%$ \\
\hline 4 & & & Smax & $4.8 \%$ & $2.1 \%$ \\
\hline 5 & & & HTan & $1.8 \%$ & $0.3 \%$ \\
\hline 6 & & & Exp & $2.0 \%$ & $1.1 \%$ \\
\hline 7 & & & Lin & $15.1 \%$ & $6.6 \%$ \\
\hline $8^{*}$ & & \multirow{4}{*}{$\log$} & $\log$ & $24.9 \%$ & $28.5 \%$ \\
\hline 9 & & & Sin & $14.8 \%$ & $13.3 \%$ \\
\hline $10 *$ & & & Smax & $32.3 \%$ & $18.2 \%$ \\
\hline 11 & & & HTan & $12.2 \%$ & $3.2 \%$ \\
\hline 12 & & \multirow{8}{*}{$\operatorname{Sin}$} & Exp & $11.9 \%$ & $2.4 \%$ \\
\hline 13 & & & Lin & $4.9 \%$ & $2.6 \%$ \\
\hline 14 & & & $\log$ & $7.3 \%$ & $3.2 \%$ \\
\hline 15 & & & Sin & $5.3 \%$ & $2.7 \%$ \\
\hline 16 & & & Smax & $5.0 \%$ & $2.4 \%$ \\
\hline 17 & & & HTan & $7.5 \%$ & $2.9 \%$ \\
\hline 18 & & & Exp & $6.9 \%$ & $3.2 \%$ \\
\hline 19 & & & Lin & $13.7 \%$ & $12.5 \%$ \\
\hline $20 *$ & & \multirow{5}{*}{ HTan } & Log & $24.9 \%$ & $24.1 \%$ \\
\hline 21 & & & $\operatorname{Sin}$ & $19.6 \%$ & $25.2 \%$ \\
\hline $22 *$ & & & Smax & $33.1 \%$ & $20.5 \%$ \\
\hline 23 & & & HTan & $13.6 \%$ & $8.0 \%$ \\
\hline 24 & & & Exp & $16.9 \%$ & $2.4 \%$ \\
\hline 25 & & \multirow{7}{*}{ Exp } & Lin & $11.6 \%$ & $2.7 \%$ \\
\hline 26 & & & $\log$ & $17.7 \%$ & $5.4 \%$ \\
\hline 27 & & & Sin & $13.8 \%$ & $4.4 \%$ \\
\hline 28 * & & & Smax & $22.3 \%$ & $11.9 \%$ \\
\hline 29 & \multirow{26}{*}{2} & & HTan & $12.4 \%$ & $2.4 \%$ \\
\hline 30 & & & $\operatorname{Exp}$ & $8.1 \%$ & $3.0 \%$ \\
\hline 31 & & & Lin & $1.5 \%$ & $1.2 \%$ \\
\hline 32 & & \multirow{5}{*}{ Lin } & $\log$ & $2.1 \%$ & $0.6 \%$ \\
\hline 33 & & & Sin & $1.4 \%$ & $1.4 \%$ \\
\hline 34 & & & Smax & $1.1 \%$ & $1.4 \%$ \\
\hline 35 & & & HTan & $1.9 \%$ & $0.6 \%$ \\
\hline 36 & & & Exp & $2.2 \%$ & $0.6 \%$ \\
\hline 37 & & \multirow{6}{*}{$\log$} & Lin & $9.3 \%$ & $2.1 \%$ \\
\hline 38 & & & Log & $7.9 \%$ & $1.7 \%$ \\
\hline $39 *$ & & & Sin & $16.4 \%$ & $4.7 \%$ \\
\hline 40 & & & Smax & $18.2 \%$ & $2.6 \%$ \\
\hline $41 *$ & & & HTan & $15.8 \%$ & $3.5 \%$ \\
\hline 42 & & & Exp & $12.1 \%$ & $2.9 \%$ \\
\hline 43 & & \multirow{6}{*}{ Sin } & Lin & $5.4 \%$ & $1.8 \%$ \\
\hline 44 & & & $\log$ & $1.7 \%$ & $1.7 \%$ \\
\hline 45 & & & Sin & $3.6 \%$ & $2.0 \%$ \\
\hline 46 & & & Smax & $3.9 \%$ & $1.8 \%$ \\
\hline 47 & & & HTan & $3.8 \%$ & $1.5 \%$ \\
\hline 48 & & & Exp & $4.6 \%$ & $2.1 \%$ \\
\hline 49 & & \multirow{6}{*}{ HTan } & Lin & $9.9 \%$ & $2.9 \%$ \\
\hline 50 & & & $\log$ & $7.7 \%$ & $3.2 \%$ \\
\hline 51 & & & Sin & $9.2 \%$ & $7.5 \%$ \\
\hline $52 *$ & & & Smax & $18.8 \%$ & $5.6 \%$ \\
\hline $53 *$ & & & HTan & $15.6 \%$ & $3.5 \%$ \\
\hline 54 & & & Exp & $9.9 \%$ & $2.0 \%$ \\
\hline
\end{tabular}


Table A3. Cont.

\begin{tabular}{|c|c|c|c|c|c|}
\hline \multirow{2}{*}{ Number } & \multirow{2}{*}{ Class } & \multicolumn{2}{|c|}{ Activation Function } & \multirow{2}{*}{$\begin{array}{c}\text { Training Set } \\
\mathrm{pNEP}\end{array}$} & \multirow{2}{*}{$\begin{array}{c}\text { Test Set } \\
\mathrm{pNEP}\end{array}$} \\
\hline & & Hidden Layer & Output Layer & & \\
\hline 55 & \multirow{6}{*}{2} & \multirow{6}{*}{ Exp } & Lin & $11.4 \%$ & $2.0 \%$ \\
\hline 56 & & & $\log$ & $11.5 \%$ & $10.2 \%$ \\
\hline 57 & & & Sin & $8.0 \%$ & $1.7 \%$ \\
\hline $58 *$ & & & Smax & $15.9 \%$ & $3.2 \%$ \\
\hline 59 & & & HTan & $9.1 \%$ & $2.0 \%$ \\
\hline 60 & & & Exp & $9.7 \%$ & $3.0 \%$ \\
\hline 61 & \multirow{30}{*}{3} & \multirow{6}{*}{ Lin } & Lin & $0.5 \%$ & $0.2 \%$ \\
\hline 62 & & & $\log$ & $1.3 \%$ & $1.2 \%$ \\
\hline 63 & & & $\operatorname{Sin}$ & $0.7 \%$ & $0.2 \%$ \\
\hline 64 & & & Smax & $1.2 \%$ & $1.5 \%$ \\
\hline 65 & & & HTan & $1.4 \%$ & $1.5 \%$ \\
\hline 66 & & & Exp & $0.9 \%$ & $0.9 \%$ \\
\hline 67 & & \multirow{6}{*}{$\log$} & Lin & $7.0 \%$ & $2.6 \%$ \\
\hline 68 & & & $\log$ & $8.3 \%$ & $2.7 \%$ \\
\hline 69 & & & Sin & $6.2 \%$ & $1.7 \%$ \\
\hline 70 & & & Smax & $12.9 \%$ & $2.1 \%$ \\
\hline $71 *$ & & & HTan & $11.2 \%$ & $4.4 \%$ \\
\hline $72 *$ & & & Exp & $9.4 \%$ & $2.7 \%$ \\
\hline 73 & & \multirow{7}{*}{ Sin } & Lin & $3.8 \%$ & $2.4 \%$ \\
\hline 74 & & & $\log$ & $4.5 \%$ & $1.4 \%$ \\
\hline 75 & & & Sin & $3.1 \%$ & $2.4 \%$ \\
\hline 76 & & & Smax & $3.8 \%$ & $1.1 \%$ \\
\hline 77 & & & HTan & $3.8 \%$ & $2.0 \%$ \\
\hline 78 & & & Exp & $4.4 \%$ & $1.8 \%$ \\
\hline 79 & & & Lin & $7.6 \%$ & $3.0 \%$ \\
\hline $80 *$ & & \multirow{5}{*}{ HTan } & Log & $13.9 \%$ & $7.2 \%$ \\
\hline 81 & & & $\operatorname{Sin}$ & $6.0 \%$ & $1.8 \%$ \\
\hline 82 * & & & Smax & $10.8 \%$ & $8.9 \%$ \\
\hline 83 & & & HTan & $10.1 \%$ & $3.0 \%$ \\
\hline 84 & & & Exp & $6.0 \%$ & $2.3 \%$ \\
\hline 85 & & \multirow{6}{*}{ Exp } & Lin & $7.7 \%$ & $2.1 \%$ \\
\hline 86 & & & Log & $4.4 \%$ & $3.0 \%$ \\
\hline 87 & & & Sin & $5.1 \%$ & $1.8 \%$ \\
\hline 88 * & & & Smax & $12.5 \%$ & $2.1 \%$ \\
\hline 89 & & & HTan & $6.8 \%$ & $2.7 \%$ \\
\hline 90 & & & Exp & $7.0 \%$ & $2.1 \%$ \\
\hline
\end{tabular}

* The best five networks for each class are bold.

\section{References}

1. Akhtaruzzaman, M.; Boubaker, S.; Lucey, B.M.; Sensoy, A. Is gold a hedge or safe haven asset during COVID-19 crisis? Econ Model. 2021, 102, 105588. [CrossRef]

2. $\quad$ Baker, S.R.; Bloom, N.; Davis, S.J.; Kost, K.J.; Sammon, M.C.; Viratyosin, T. The Unprecedented Stock Market Impact of COVID-19; NBER Working Paper No. 26945; National Bureau of Economic Research: Cambridge, MA, USA, 2020.

3. Zhang, D.; Hu, M.; Ji, Q. Financial markets under the global pandemic of COVID-19. Finance Res. Lett. 2020, 36, 101528. [CrossRef]

4. International Energy Agency. Global Energy Review 2020. Available online: https://iea.blob.core.windows.net/assets/7e802f6a0b30-4714-abb1-46f21a7a9530/Global_Energy_Review_2020.pdf (accessed on 15 October 2021).

5. Akhtaruzzaman, M.; Boubaker, S.; Chiah, M.; Zhong, A. COVID-19 and oil price risk exposure. Financ. Res. Lett. 2021, 42, 101882. [CrossRef]

6. Sharif, A.; Aloui, C.; Yarovaya, L. COVID-19 pandemic, oil prices, stock market, geopolitical risk and policy uncertainty nexus in the US economy: Fresh evidence from the wavelet-based approach. Int. Rev. Financ. Anal. 2020, 70, 101496. [CrossRef]

7. Abuzayed, B.; Al-Fayoumi, N. Risk spillover from crude oil prices to GCC stock market returns: New evidence during the COVID-19 outbreak. N. Am. J. Econ. Financ. 2021, 58, 101476. [CrossRef]

8. Jones, C.M.; Kaul, G. Oil and the stock markets. J. Finance 1996, 51, 463-491. [CrossRef]

9. Basher, S.A.; Sadorsky, P. Oil price risk and emerging stock markets. Glob. Financ. J. 2006, 17, 224-251. [CrossRef]

10. Nandha, M.; Faff, R. Does oil move equity prices? A global view. Energy Econ. 2008, 30, 986-997. [CrossRef] 
11. Al Rahahleh, N.; Bhatti, M.I. Co-movement measure of information transmission on international equity markets. Phys. A Stat. Mech. Appl. 2017, 470, 119-131. [CrossRef]

12. Hsiao, C.Y.-L.; Lin, W.; Wei, X.; Yan, G.; Li, S.; Sheng, N. The Impact of International Oil Prices on the Stock Price Fluctuations of China's Renewable Energy Enterprises. Energies 2019, 12, 4630. [CrossRef]

13. Zhu, J.; Song, Q.; Streimikiene, D. Multi-Time Scale Spillover Effect of International Oil Price Fluctuation on China's Stock Markets. Energies 2020, 13, 4641. [CrossRef]

14. Wu, M.-H.; Ni, Y.-S. The effects of oil prices on inflation, interest rates and money. Energy 2011, 36, 4158-4164. [CrossRef]

15. Golub, S. Oil prices and exchange rates. Econ. J. 1983, 93, 576-593. [CrossRef]

16. Zhang, Y.-J.; Fan, Y.; Tsai, H.-T.; Wei, Y.-M. Spillover effect of US dollar exchange rate on oil prices. J. Policy Model. 2008, 30, 973-991.

17. Reboredo, J.C.; Rivera-Castro, M.A. A wavelet decomposition approach to crude oil price and exchange rate dependence. Econ. Model. 2013, 32, 42-57. [CrossRef]

18. De Truchis, G.; Keddad, B. On the risk comovements between the crude oil market and U.S. dollar exchange rates. Econ. Model. 2016, 52, 206-215. [CrossRef]

19. Śmiech, S.; Papież, M.; Rubaszek, M.; Snarska, M. The role of oil price uncertainty shocks on oil-exporting countries. Energy Econ. 2021, 93, 105028. [CrossRef]

20. Antonakakis, N.; Chatziantoniou, I.; Filis, G. Dynamic spillovers of oil price shocks and economic policy uncertainty. Energy Econ. 2014, 44, 433-447. [CrossRef]

21. Villar, J.A.; Joutz, F.L. The relationship between crude oil and natural gas prices. Energy Inf. Adm. Off. Oil Gas 2006, 1-43. Available online: http:/ / aceer.uprm.edu/aceer/pdfs/CrudeOil_NaturalGas.pdf (accessed on 15 October 2021).

22. Ji, Q.; Geng, J.-B.; Fan, Y. Separated influence of crude oil prices on regional natural gas import prices. Energy Policy 2014, 70, 96-105. [CrossRef]

23. Lin, B.; Li, J. The spillover effects across natural gas and oil markets: Based on the VEC-MGARCH framework. Appl. Energy 2015, 155, 229-241. [CrossRef]

24. Ji, Q.; Geng, J.-B.; Tiwari, A.K. Information spillovers and connectedness networks in the oil and gas markets. Energy Econ. 2018, 75, 71-84. [CrossRef]

25. Zhang, D.; Shi, M.; Shi, X. Oil indexation, market fundamentals, and natural gas prices: An investigation of the Asian premium in natural gas trade. Energy Econ. 2018, 69, 33-41. [CrossRef]

26. Wu, F.; Guan, Z.; Myers, R.J. Volatility spillover effects and cross hedging in corn and crude oil futures. J. Futures Mark. 2011, 31, 1052-1075. [CrossRef]

27. Walid, M.; Shawkat, H.; Nguyen, D.K.; Yoon, S.-M. Dynamic spillovers among major energy and cereal commodity prices. Energy Econ. 2014, 43, 225-243.

28. Taghizadeh-Hesary, F.; Rasoulinezhad, E.; Yoshino, N. Volatility Linkages between Energy and Food Prices: Case of Selected Asian Countries; Asian Development Bank Institute Working Paper 829; Asian Development Bank Institute: Tokyo, Japan, 2018. Available online: https://www.adb.org/sites/default/files/publication/411176/adbi-wp829.pdf (accessed on 15 April 2020).

29. Vo, D.H.; Vu, T.N.; Vo, A.T.; McAleer, M. Modeling the Relationship between Crude Oil and Agricultural Commodity Prices. Energies 2019, 12, 1344. [CrossRef]

30. Ewing, B.T.; Malik, F. Volatility transmission between gold and oil futures under structural breaks. Int. Rev. Econ. Financ. 2013, 25, 113-121.

31. Chen, R.; Xu, J. Forecasting volatility and correlation between oil and gold prices using a novel multivariate GAS model. Energy Econ. 2019, 78, 379-391.

32. Sari, R.; Hammoudeh, S.; Soytas, U. Dynamics of oil price, precious metal prices and exchange rate. Energy Econ. 2010, 32, 351-362. [CrossRef]

33. Popp, J.; Oláh, J.; Fekete, M.F.; Lakner, Z.; Máté, D. The Relationship between Prices of Various Metals, Oil and Scarcity. Energies 2018, 11, 2392. [CrossRef]

34. Azadeh, A.; Moghaddam, M.; Khakzad, M.; Ebrahimipour, V. A flexible neural network-fuzzy mathematical programming algorithm for improvement of oil price estimation and forecasting. Comput. Ind. Eng. 2012, 62, 421-430. [CrossRef]

35. Chiroma, H.; Abdulkareem, S.; Herawan, T. Evolutionary neural network model for West Texas Intermediate crude oil price prediction. Appl. Energy 2015, 142, 266-273. [CrossRef]

36. Wang, J.; Wang, J. Forecasting energy market indices with recurrent neural networks: Case study of crude oil price fluctuations. Energy 2016, 102, 365-374. [CrossRef]

37. Liu, D.; Liang, Y.; Zhang, L.; Lung, P.; Ullah, R. Implied volatility forecast and option trading strategy. Int. Rev. Econ. Financ. 2021, 71, 943-954. [CrossRef]

38. Mohamed, M.M.; El-Masry, A.A. Oil price forecasting using gene expression programming and artificial neural networks. Econ. Model. 2016, 54, 40-53.

39. Yusof, Y.; Mustaffa, Z. A review on optimization of least squares support vector machine for time series forecasting. Int. J. Artif. Intell. Appl. 2016, 7, 35-49. [CrossRef]

40. Zhao, Y.; Li, J.; Yu, L. A deep learning ensemble approach for crude oil price forecasting. Energy Econ. 2017, 66, 9-16. [CrossRef] 
41. Huang, L.; Wang, J. Global crude oil price prediction and synchronization based accuracy evaluation using random wavelet neural network. Energy 2018, 151, 875-888. [CrossRef]

42. Safari, A.; Davallou, M. Oil price forecasting using a hybrid model. Energy 2018, 148, 49-58. [CrossRef]

43. Li, T.; Hu, Z.; Jia, Y.; Wu, J.; Zhou, Y. Forecasting crude oil prices using ensemble empirical mode decomposition and sparse Bayesian learning. Energies 2018, 11, 1882. [CrossRef]

44. Wang, M.; Zhao, L.; Du, R.; Wang, C.; Chen, L.; Tian, L.; Stanley, H.E. A novel hybrid method of forecasting crude oil prices using complex network science and artificial intelligence algorithms. Appl. Energy 2018, 220, 480-495. [CrossRef]

45. Ding, Y. A novel decompose-ensemble methodology with AIC-ANN approach for crude oil forecasting. Energy 2018, 154, 328-336. [CrossRef]

46. Li, T.; Zhou, Y.; Li, X.; Wu, J.; He, T. Forecasting daily crude oil prices using improved CEEMDAN and ridge regression-based predictors. Energies 2019, 12, 3603. [CrossRef]

47. Wu, J.; Miu, F.; Li, T. Daily Crude Oil Price Forecasting Based on Improved CEEMDAN, SCA, and RVFL: A Case Study in WTI Oil Market. Energies 2020, 13, 1852. [CrossRef]

48. Puka, R.; Łamasz, B. Using Artificial Neural Networks to Find Buy Signals for WTI Crude Oil Call Options. Energies 2020, 13, 4359. [CrossRef]

49. Puka, R.; Łamasz, B.; Michalski, M. Effectiveness of Artificial Neural Networks in Hedging against WTI Crude Oil Price Risk. Energies 2021, 14, 3308. [CrossRef]

50. Dbouk, W.; Jamali, I. Predicting daily oil prices: Linear and non-linear models. Res. Int. Bus. Finance 2018, 46, 149-165. [CrossRef]

51. Mohamed, Z.E. Using the artificial neural networks for prediction and validating solar radiation. J. Egypt. Math. Soc. 2019, 27, 47. [CrossRef]

52. Srihari, S. Backpropagation. Available online: https://cedar.buffalo.edu/ \{\}srihari/CSE574/Chap5/Chap5.3-BackProp.pdf (accessed on 21 October 2021).

53. Parr, T.; Howard, J. The Matrix Calculus You Need For Deep Learning. Available online: https://explained.ai/matrix-calculus (accessed on 23 December 2020).

54. Peng, C.-C.; Magoulas, G.D. Nonmonotone BFGS-trained recurrent neural networks for temporal sequence processing. Appl. Math. Comput. 2011, 217, 5421-5441. [CrossRef]

55. QuikVol Tool. WTI (LO) Volatility and Skew. Available online: https://www.cmegroup.com/tools-information/quikstrike/ pricing-volatility-strategy-tools/ quikvol-tool.html (accessed on 15 April 2020).

56. Welcome to NYMEX WTI Light Sweet Crude Oil Futures. Available online: https://www.cmegroup.com/trading/why-futures/ welcome-to-nymex-wti-light-sweet-crude-oil-futures.html (accessed on 15 December 2020).

57. Chapter 550. Light Sweet Crude Oil European Financial Option. Available online: https://www.cmegroup.com/content/dam/ cmegroup/rulebook/NYMEX/5/550.pdf (accessed on 15 December 2020).

58. Black, F. The pricing of commodity contracts. J. Financ. Econ. 1976, 3, 167-179. [CrossRef]

59. Hull, J. Option, Futures and Other Derivatives, 8th ed.; Pearson: Boston, MA, USA, 2012.

60. Łamasz, B.; Iwaszczuk, N. Crude Oil Option Market Parameters and Their Impact on the Cost of Hedging by Long Strap Strategy. Int. J. Energy Econ. Policy 2020, 10, 471-480. [CrossRef]

61. Clark, I.J. Commodity Option Pricing: A Practioner's Guide; Wiley Finance Series; John Wiley \& Sons: Padstow, UK, 2014.

62. Yousaf, A.; Asif, R.M.; Shakir, M.; Rehman, A.U.; Adrees, M.S. An Improved Residential Electricity Load Forecasting Using a Machine-Learning-Based Feature Selection Approach and a Proposed Integration Strategy. Sustainability 2021, 13, 6199. [CrossRef]

63. Khan, R.; Yang, Q.; Ullah, I.; Rehman, A.R.; Bin Tufail, A.; Noor, A.; Rehman, A.; Cengiz, K. 3D Convolutional Neural Networks based automatic modulation classification in the presence of channel noise. IET Commun. 2021, 15, 1-13. [CrossRef] 